ARTICLE

\title{
Enzymatic spiroketal formation via oxidative rearrangement of pentangular polyketides
}

\author{
Britta Frensch (10 1, Thorsten Lechtenberg ${ }^{1}$, Michel Kather ${ }^{2}$, Zeynep Yunt ${ }^{3}$, Martin Betschart ${ }^{4}$,
}

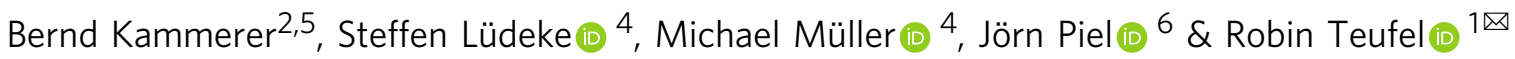

The structural complexity and bioactivity of natural products often depend on enzymatic redox tailoring steps. This is exemplified by the generation of the bisbenzannulated $[5,6]$ spiroketal pharmacophore in the bacterial rubromycin family of aromatic polyketides, which exhibit a wide array of bioactivities such as the inhibition of HIV reverse transcriptase or DNA helicase. Here we elucidate the complex flavoenzyme-driven formation of the rubromycin pharmacophore that is markedly distinct from conventional (bio)synthetic strategies for spiroketal formation. Accordingly, a polycyclic aromatic precursor undergoes extensive enzymatic oxidative rearrangement catalyzed by two flavoprotein monooxygenases and a flavoprotein oxidase that ultimately results in a drastic distortion of the carbon skeleton. The one-pot in vitro reconstitution of the key enzymatic steps as well as the comprehensive characterization of reactive intermediates allow to unravel the intricate underlying reactions, during which four carbon-carbon bonds are broken and two $\mathrm{CO}_{2}$ become eliminated. This work provides detailed insight into perplexing redox tailoring enzymology that sets the stage for the (chemo)enzymatic production and bioengineering of bioactive spiroketal-containing polyketides.

\footnotetext{
${ }^{1}$ Faculty of Biology, University of Freiburg, Schänzlestrasse 1, 79104 Freiburg, Germany. ${ }^{2}$ BIOSS Center for Biological Signaling Studies, University of Freiburg 79104 Freiburg, Germany. ${ }^{3}$ Department of Molecular Biology and Genetics, Koç University, Istanbul 34450, Turkey. ${ }^{4}$ Institute of Pharmaceutical Sciences, University of Freiburg, 79104 Freiburg, Germany. ${ }^{5}$ Hermann Staudinger Graduate School, University of Freiburg, 79104 Freiburg, Germany. ${ }^{6}$ Institute of Microbiology, Eidgenössische Technische Hochschule (ETH) Zürich, 8093 Zürich, Switzerland. ${ }^{凶}$ email: robin.teufel@zbsa.uni-freiburg.de
} 
T he benastatins, pradimicins, fredericamycins, xantholipins (among others), as well as the rubromycin family belong to a growing group of biosynthetically related aromatic type II polyketide natural products with extended "pentangular" architecture that are produced by numerous actinobacterial species ${ }^{1-8}$. The intensely colored rubromycins comprise various griseorhodins (e.g., griseorhodin A (1)), hyaluromycin, purpuromycin, heliquinomycin, as well as the eponymous rubromycins (e.g., $\beta$ rubromycin (2) $)^{2,9-12}$. Often, these compounds act as potent enzyme inhibitors and $\mathbf{2}$ was consequently suggested as a lead structure for drug development ${ }^{13}$. The hallmark structural feature of the rubromycins is a bisbenzannulated [5,6]-spiroketal pharmacophore that disrupts the planarity of the polycyclic, aromatic carbon backbone (Fig. 1) ${ }^{13}$. Even though 2 was first described in $1953^{11}$ (Fig. 1), it took almost half a century before the total synthesis of a rubromycin polyketide was achieved owing to their intricate structures ${ }^{12,14}$. In fact, synthetic strategies for the griseorhodins have yet to be reported, which are distinguished by even more complex, highly oxygenated pharmacophores such as the epoxyspiroketal of $\mathbf{1}^{12}$.

Moreover, details on the biosynthesis of the rubromycins and the spiroketal moiety remain scarce. First insights originated from extensive gene-inactivation studies with the griseorhodin ( $g r h$ ) A biosynthetic gene cluster of Streptomyces sp. JP95 isolated from the marine tunicate Aplidium lenticulum, which was expressed in the heterologous producer $S$. albus sp. J10749,10. Initial steps resemble typical type II polyketide pathways involving a minimal polyketide synthase (PKS) that likely utilizes an acetyl-CoA starter unit and 12 malonyl-CoA extender units to generate a highly reactive acyl-carrier protein (ACP)-bound poly- $\beta$-ketone chain. Following enzyme-catalyzed regioselective ketoreduction, cyclization, aromatization and ACP elimination, further tailoring reactions modify the polyketide backbone and lead to the advanced and highly oxidized intermediate collinone (3) (previously also isolated from a heterologous producer expressing parts of the rubromycin biosynthetic gene cluster ${ }^{15}$ ), which may serve as a direct precursor for spiroketalization ${ }^{10}$. This would necessitate an extensive oxidative backbone rearrangement as well as the elimination of two $C_{1}$ units, which may be mediated by mechanistically versatile flavin-dependent enzymes $^{16-22}$ that often facilitate redox tailoring reactions in natural product biosynthesis (Fig. 1) ${ }^{16,19}$.

Here, we report the full in vitro reconstitution of enzymatic spiroketal formation in the biosynthesis of rubromycintype polyketides. We elucidate the conversion of $\mathbf{3}$ into the
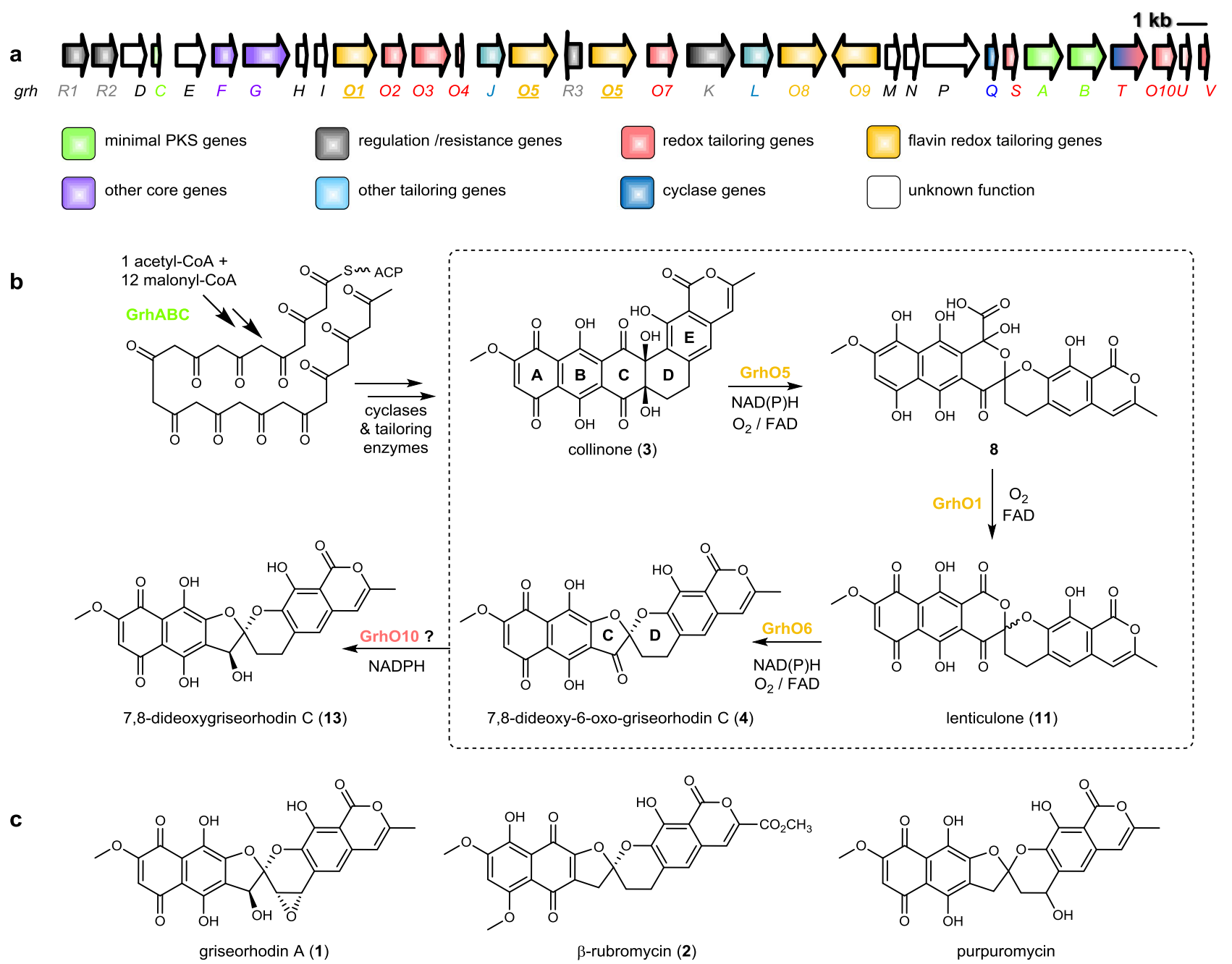

Fig. 1 Overview of the proposed biosynthesis of bacterial rubromycin-type polyketides and final pathway products. a Griseorhodin A biosynthetic gene cluster encoding, e.g., the minimal type II polyketide synthase (PKS), cyclases, and tailoring enzymes ${ }^{9}$. $\mathbf{b}$ Initial steps afford a reactive acyl-carrier protein (ACP)-bound poly- $\beta$-ketone, which is subsequently cyclized and modified to $\mathbf{3}$. Compounds $\mathbf{3}$ and $\mathbf{1 1}$ were previously identified in the course of gene deletion experiments ( $\Delta$ grhO5 and $\Delta$ grhO6, respectively, encoding flavin-dependent tailoring enzymes investigated in this work) and assigned as putative advanced intermediates ${ }^{10}$. The conversion of $\mathbf{3}$ into $\mathbf{4}$ via $\mathbf{8}$ and $\mathbf{1 1}$ (dashed box) and additional intermediates was elucidated in this work. A ketoreductase (presumably Grh010) then converts 4 into 13. c Examples of mature rubromycins likely formed from $\mathbf{1 3 .}$ 
[5,6]-spiroketal-containing 7,8-dideoxy-6-oxo-griseorhodin C (4) via various reactive intermediates by the concerted action of the flavoprotein monooxygenases GrhO5 and GrhO6, as well as the flavoprotein oxidase GrhO1 that are encoded by the grh gene cluster. This process is primarily mediated by the multifunctional monooxygenase GrhO5 that oxidatively rearranges the carbon backbone and ultimately forms a [6,6]-spiroketal and is assisted by GrhO1, before the ring-contracting GrhO6 generates the $[5,6]$ spiroketal pharmacophore found in mature rubromycin polyketides (Fig. 1).

\section{Results}

Flavoprotein monooxygenase GrhO5 initiates spiroketal formation by rapid collinone reduction. S. albus sp. J1074 KR8 $(\Delta g r h$ O5) was previously reported to produce $\mathbf{3}$ as major shunt metabolite, which may thus represent the native substrate of GrhO5 ${ }^{10}$. To investigate this, 3 was isolated from the $S$. albus mutant, while GrhO5 (fused with an N-terminal maltose binding protein tag) was obtained from the heterologous producer Escherichia coli BL21 DE3 (see Online Methods section for details on gene cloning as well as production and purification of enzymes and compounds). GrhO5 is predicted to function as flavoprotein monooxygenase based on the amino acid sequence ${ }^{10}$ and is homologous to the $\mathrm{NAD}(\mathrm{P}) \mathrm{H}$ - and FAD-dependent class $\mathrm{A}$ flavoprotein monooxygenases with "glutathione reductase type" Rossmann fold ${ }^{21}$. Typically, these enzymes catalyze aromatic hydroxylation reactions via an electrophilic flavin-C4ahydroperoxide oxygenating species, while some members instead act as Baeyer-Villiger monooxygenases (BVMOs) that employ a nucleophilic flavin-C4a-peroxide anion ${ }^{22,23}$. The purified enzyme showed an intense yellow coloration indicative of a bound flavin cofactor that was further determined as flavin adenine dinucleotide (FAD; Supplementary Fig. 1). Under optimized assay conditions, GrhO5-dependent consumption of 3 could indeed be observed by UV-Vis spectroscopy in the presence of the electron donor NADPH $(\approx 20 \%$ activity with NADH; see Supplementary Fig. 2 for kinetics). To further investigate this and elucidate the reaction course, samples from enzyme reactions were quenched after different incubation times, the compounds extracted and then analyzed by reverse-phase high performance liquid chromatography (RP-HPLC).

First, GrhO5 catalyzed the rapid conversion of $\mathbf{3}$ into intermediate 5 (Supplementary Fig. 3). Extracted 5 featured a distinct UV-Vis spectrum and intense yellow color, as compared to the purple-red 3. Liquid chromatography high-resolution mass spectrometry (LC-HRMS) indicated that 5 represents a reduced form of 3, which spontaneously reoxidized in the presence of $\mathrm{O}_{2}$, as shown by the color change and confirmed by RP-HPLC (Supplementary Fig. 3). This was further supported by the nonenzymatic chemical reduction of $\mathbf{3}$ (using Ti(III) citrate or DTT), which also afforded 5 (Supplementary Fig. 3a). Notably, compared to the much faster GrhO5-dependent $\mathbf{5}$ formation, $\mathrm{NADPH}( \pm$ free FAD) only reduced 3 at very low rates (Fig. 2 and Supplementary Fig. 2c). To solve the structure of $\mathbf{5}$ and of other compounds described below, large scale enzymatic assays were conducted. Anaerobic conditions enabled the complete conversion of 3 into $\mathbf{5}$, which was afterwards extracted, purified via RPHPLC, and lyophilized. NMR spectroscopy $\left({ }^{1} \mathrm{H}\right.$ NMR, ${ }^{13} \mathrm{C}$ NMR, HSQC, HMBC, Supplementary Figs. 4-7) in a sealed, anaerobic tube then identified $\mathbf{5}$ as ring A-reduced dihydrocollinone featuring a naphthohydroquinone moiety (Fig. 3a).

Dihydrocollinone is oxygenolytically cleaved by GrhO5 and converted to secocollinone. Compound $\mathbf{5}$ was not further processed by GrhO5 under anaerobic conditions, suggesting a succeeding $\mathrm{O}_{2}$-dependent reaction probably in form of an oxygenation. Indeed, in presence of $\mathrm{O}_{2}, 3$ was first reduced to 5 and then further converted; however, significantly reduced amounts of putative intermediates/products were subsequently retrieved. We thus suspected that GrhO5 converts 5 into a labile and/or insoluble intermediate. To investigate this, chemical derivatization of the putative intermediate was attempted after quenching of the enzyme assay. Methylation of the reactive phenol groups by dimethyl sulfate (DMS) proved suitable and afforded a completely methylated and reduced derivative (6) of an enzymatically hydroxylated intermediate based on LC-HRMS and tandem MS $\left(\mathrm{MS}^{2}\right.$ ) analysis (Supplementary Fig. 9). Comprehensive NMR spectroscopy (Supplementary Figs. 10-13) of $\mathbf{6}$ revealed a ruptured D-ring as well as a hydroxylated E-ring. We propose the native intermediate to be secocollinone 7 , which is likely derivatized to 6 by non-enzymatic reduction (via NADPH), keto-enol tautomerization (that triggers water elimination at C18), and complete methylation of the free hydroxyl groups (Fig. 3a).

To confirm that 7 represents an intermediate, the time course for 6 formation was scrutinized in the GrhO5 assay. For that, samples were withdrawn at different time points, quenched, and methylated. HPLC analysis of the derivatized samples then showed the formation of significant amounts of $\mathbf{6}$ at $1 \mathrm{~min}$, a maximum amount at $3 \mathrm{~min}$, and only residual amounts after $4 \mathrm{~min}$, consistent with the envisaged formation of 7 from 5 (Fig. 3a and Supplementary Fig. 9a). Based on these results, we propose the following reaction sequence. First, ring A of $\mathbf{3}$ is reduced to $\mathbf{5}$ (Fig. 3a, step I), before aromatic hydroxylation at $\mathrm{C} 4$ of $\mathbf{5}$ (step II) prompts the first C-C bond cleavage of ring $\mathrm{D}$ via retro-aldol condensation to afford 7 (step III). The flavin-mediated hydroxylation most likely proceeds via an electrophilic flavin-C4a-hydroperoxide $\left(\mathrm{Fl}_{\mathrm{C} 4 \mathrm{aOOH}}\right)$ oxygen transferring agent, as discussed below.

Secocollinone is rearranged to the $[6,6]$-spiroketal-containing dihydrolenticulone. Concurrent with consumption of 7 , compound 8 emerged in the HPLC chromatograms, followed shortly by shunt product 9 and on-pathway intermediate 10 (Figs. 2 and $3 \mathrm{ab})$. Notably, isolated $\mathbf{8}$ proved highly unstable and LC-HRMS analysis verified the spontaneous conversion into both $\mathbf{9}$ and $\mathbf{1 0}$ (Supplementary Fig. 14). Moreover, compound 10 rapidly autooxidized to compound 11, analogous to the oxidation of 5 into 3 , as verified by RP-HPLC and LC-HRMS (Supplementary Fig. 15). Compounds 9 and 11 were only moderately stable in aqueous solution, thus explaining why prolonged incubation $(>30 \mathrm{~min})$ of 3 with GrhO5 did not yield significant amounts of enzymatic product. Surprisingly, 11 was identified as the previously reported lenticulone featuring a [6,6]-spiroketal ${ }^{10}$ and $\mathbf{1 0}$ accordingly as the respective ring A-reduced dihydrolenticulone based on LC-HRMS/MS ${ }^{2}$ analysis, UV-Vis spectra, NMR spectroscopy, and comparison with a standard acquired from S. albus sp. J1074 MP66 $\left(\Delta\right.$ grhO6) ${ }^{10}$ (Fig. 3b and Supplementary Figs. 16-19). In contrast, comprehensive NMR spectroscopy and $\mathrm{MS}^{2}$ fragmentation of shunt product 9 revealed a non-spiro compound with opened C-ring (Fig. 3b, Supplementary Figs. 20-25, and Supplementary Table 1).

To consolidate these results, we propose that 7 first undergoes retro-aldol cleavage of ring $\mathrm{C}$ generating an $\alpha$-keto aldehyde motif at C5-C6 (Fig. 3a, step IV). Then, a series or reversible steps takes place including carbonyl-hydrations, tautomerization, and ring D re-formation via hemiacetal formation (steps V-VII), before isomerization affords a C5-C6 a-hydroxy acid (step VIII). Subsequently, the C6 hydroxyl group is oxidized to the respective ketone, likely mediated by the flavin cofactor of GrhO5 (step IX). Lastly, ring $\mathrm{C}$ is reinstalled via attack of the C18 hydroxyl group on the C6-ketone to afford 8 (step X). Although highly labile $\mathbf{8}$ could not be isolated for structural elucidation by NMR, 


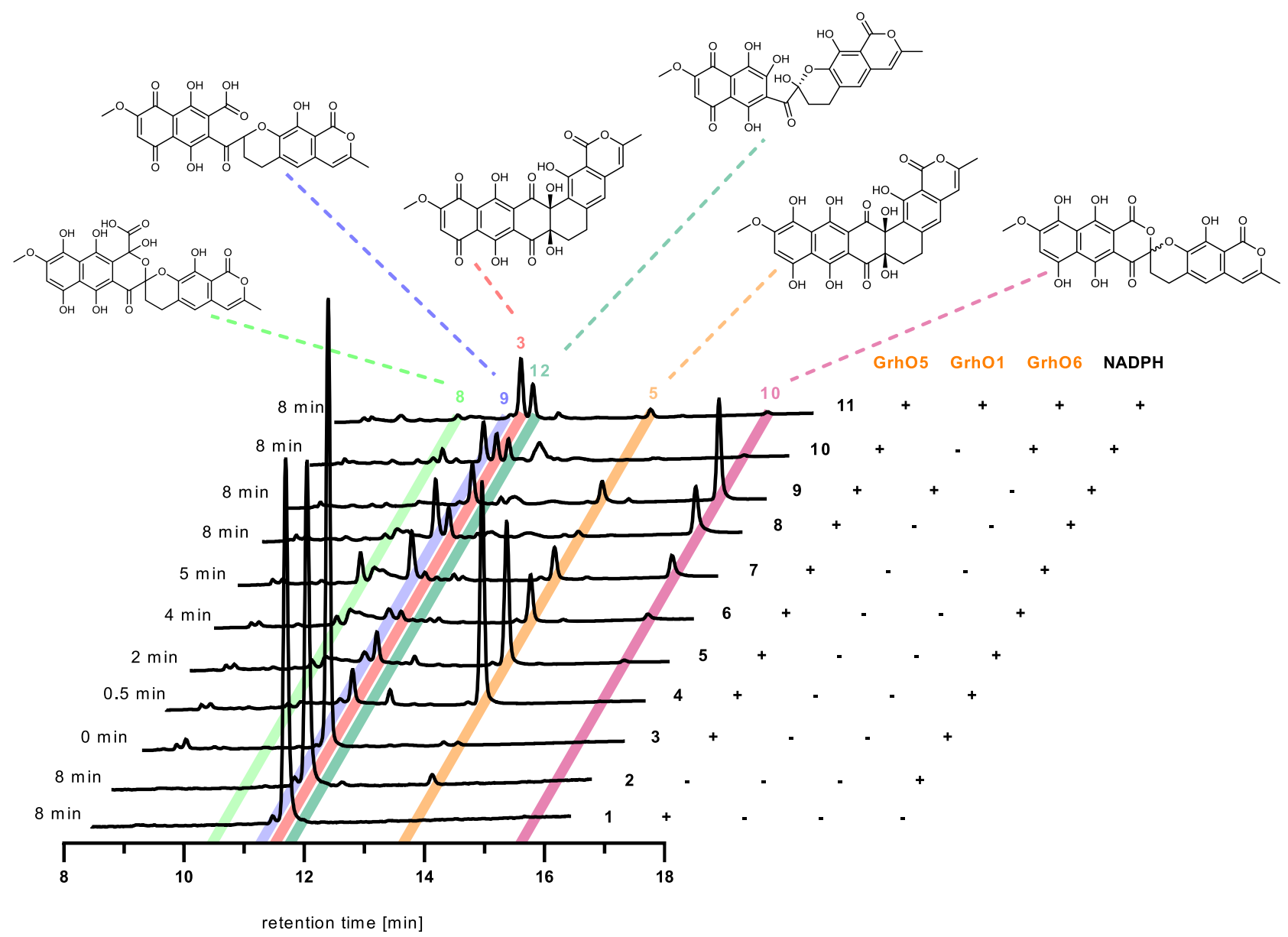

Fig. 2 Enzyme assays with substrate $\mathbf{3}$ in presence of $\mathbf{O}_{\mathbf{2}}$ (shown are the RP-HPLC chromatograms at $\boldsymbol{\lambda}=\mathbf{2 5 4} \mathbf{n m}$ ). Incubation times before reaction quenching are indicated to the left. The respective enzyme and cofactor composition is shown to the right. No conversion of $\mathbf{3}$ was observed in control assays lacking NADPH (trace 1) or GrhO5 (trace 2). Traces 3-8 show time points from the same, discontinuous assay with GrhO5, in which shunt product $\mathbf{9}$ accumulated aside from intermediate 10. Addition of GrhO1 boosted $\mathbf{1 0}$ formation and counteracted $\mathbf{9}$ formation (trace 9 ). Addition of GrhO6 (traces 10 and 11) lead to conversion of $\mathbf{1 0}$ into $\mathbf{4}$ (that rapidly forms ring-opened 12). Note that $\mathbf{7}$ is not observed due to poor separation resulting from polymerization and irreversible binding. The structures of the intermediates are shown above. The proposed enzymatic steps are presented in Fig. 3. All assays were at least conducted three times independently and representative examples are shown (for uncropped chromatograms, see Supplementary Fig. 8).

isotope-labeling studies with $\mathbf{8}$ corroborate this proposal. Accordingly, up to two ${ }^{18} \mathrm{O}$ atoms derived from $\mathrm{H}_{2}{ }^{18} \mathrm{O}$ were observed in $\mathbf{8}$ by LC-HRMS/MS ${ }^{2}$ (Supplementary Fig. 26), consistent with water-dependent $\alpha$-hydroxy acid formation (part of steps V-VIII) and incorporation of ${ }^{18} \mathrm{O}$ via reversible carbonyl hydrate formation (step VI).

Next, we propose that spontaneous oxidation of ring $\mathrm{B}$ of $\mathbf{8}$ allows the third $\mathrm{C}-\mathrm{C}$ bond cleavage via facile decarboxylation. This is enabled by an appropriately positioned C15-ketone in ring $\mathrm{B}$ that acts as electron sink, thereby producing on-pathway intermediate $\mathbf{1 0}$ after keto-enol tautomerization, before ring $\mathrm{A}$ autooxidation yields 11 (step XI, Fig. 3b). Interestingly, in addition to reduction of 3, GrhO5 was also capable of reducing 11 into 10 with NAD(P)H (Supplementary Fig. 17). Alternatively, decarboxylation can occur (without prior oxidation) through spiroketalopening enabled by the C17-ketone of ring $\mathrm{C}$ to afford shunt product 9 after tautomerization and autooxidation of ring A (step XII). To further investigate this mechanistic proposal, both 9 and 11 were enzymatically produced in presence of either ${ }^{18} \mathrm{O}_{2}$ or $\mathrm{H}_{2}{ }^{18} \mathrm{O}$. As expected, one ${ }^{18} \mathrm{O}$ label from $\mathrm{O}_{2}$ was incorporated in the eastern molecule halves of $\mathbf{9}$ and $\mathbf{1 1}$ as a result of GrhO5's oxygenase functionality (Supplementary Figs. 27 and 28). Notably, in the labeling experiments with $\mathrm{H}_{2}{ }^{18} \mathrm{O}$, both 9 and $\mathbf{1 1}$ only retained a single ${ }^{18} \mathrm{O}$-label from $\mathrm{H}_{2}{ }^{18} \mathrm{O}$ in the western molecule half (Supplementary Figs. 27 and 28 and Supplementary Tables 2-5) in contrast to the doubly labeled $\mathbf{8}$, confirming that one water-derived ${ }^{18} \mathrm{O}$ was eliminated via decarboxylation (Fig. 3b). The UV-Vis data were furthermore fully consistent with the proposed redox states of these intermediates and clearly indicated a napthohydroquinone moiety with reduced rings A and B for 5, 8, and 10 (Supplementary Fig. 29a), while spectral features of $\mathbf{3}, \mathbf{9}$, and 11 suggested oxidized quinonic A rings (Supplementary Fig. 29b).

The quinone-forming oxidase GrhO1 boosts dihydrolenticulone formation. Although GrhO5 proved sufficient for in vitro formation of $10, \approx 50 \%$ of shunt product 9 was generated. This prompted us to consider additional enzymes that could mediate the oxidation of ring $\mathrm{B}$ of $\mathbf{8}$ and thus promote formation of 10/11. Previous studies with deletion mutants suggested that GrhO1 may be involved in spiroketal maturation ${ }^{10}$. GrhO1 also seemed a prime candidate because it is a member of the vanillyl alcohol oxidase/para-cresol methylhydroxylase (VAO/PCMH) flavoenzyme family that typically catalyze (non-oxygenative) two-electron oxidation reactions rather than hydroxylations, although some exceptions exist ${ }^{18,24}$. Hence, we supplemented our in vitro GrhO5 assays with heterologously 

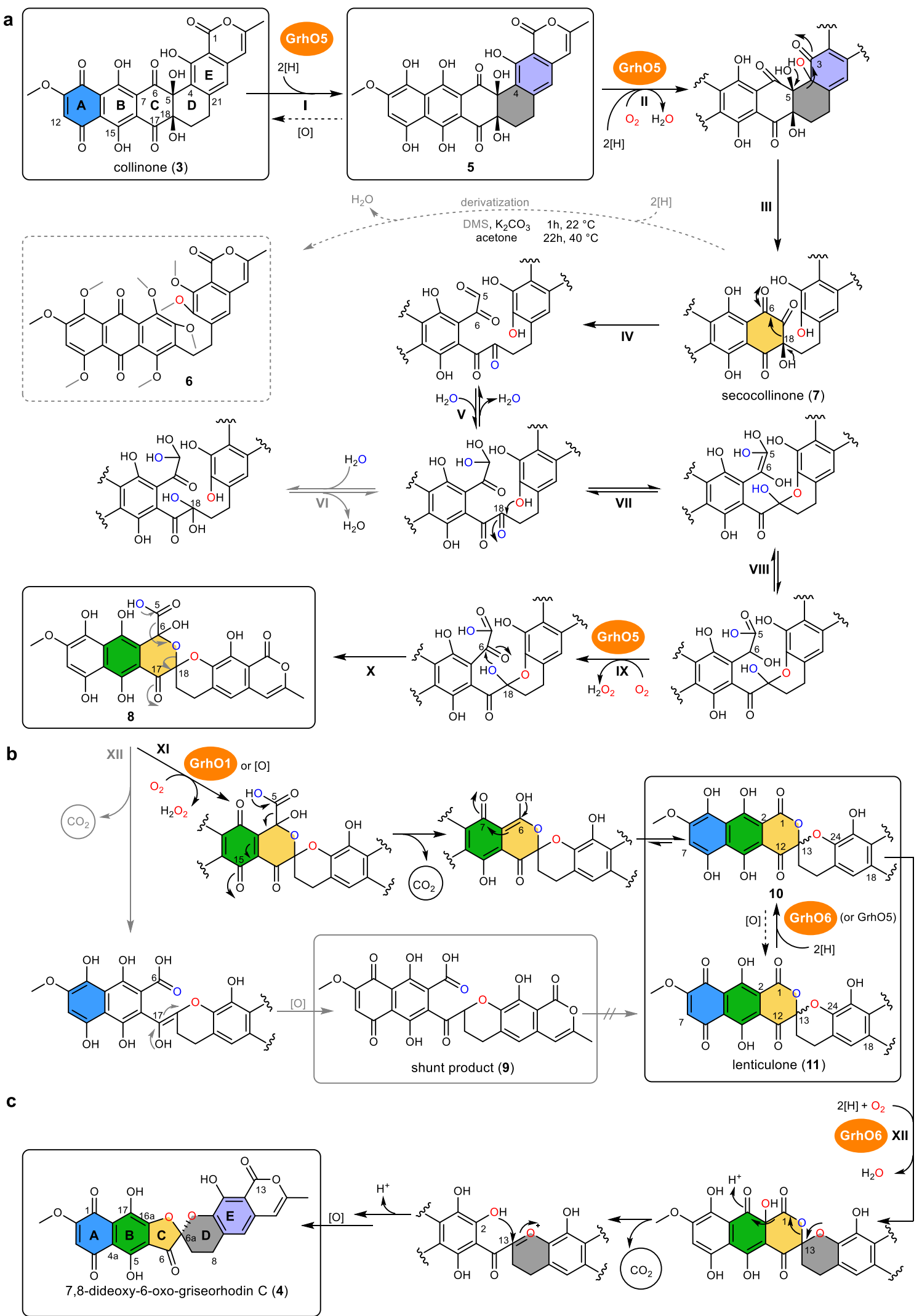

produced polyhistidine-tagged GrhO1 that features a covalently bound flavin (Supplementary Fig. 30). Indeed, the presence of GrhO1 minimized production of $\mathbf{9}$ and boosted formation of $\mathbf{1 0}$ (Fig. 2), whereas purified 9 (and its reduced form) could not be converted by GrhO1 (Supplementary Fig. 31). These results indicate that GrhO1 indeed catalyzes the selective oxidation of ring B of $\mathbf{8}$ (step XI, Fig. 3b) and assists GrhO5 in [6,6]-spiroketal formation. Next, we analyzed the GrhO5 and GrhO1-produced 11 by circular dichroism (CD) spectroscopy, revealing a racemic mixture. Presumably, enzymatically formed $\mathbf{1 1}$ is chiral at first but undergoes 
Fig. 3 Proposed spiroketal formation in rubromycin polyketide biosynthesis. Redox steps catalyzed by GrhO5, GrhO1, and GrhO6 are highlighted with the respective enzyme symbols. Other steps may be catalyzed or occur spontaneously in the enzymes' active sites, see text for details. The rings A-E of compounds that undergo modification in the ensuing biosynthetic step are color-coded according to the final product $\mathbf{4}$ (bottom left); important carbons are numbered for each step. Note that the carbon numbering of intermediates up to $\mathbf{8}$ is according to compound $\mathbf{3}$, whereas different carbon numberings are used for 10/11 and the final product 4. Oxygen atoms derived from $\mathrm{O}_{2}$ and $\mathrm{H}_{2} \mathrm{O}$ (based on isotope-labeling experiments) are highlighted in red and blue, respectively. Water-derived ${ }^{18} \mathrm{O}$ is most likely also incorporated from spontaneous and reversible keto hydration as shown in step $\mathrm{VI}$ (gray arrows). a Proposed GrhO5-mediated conversion of $\mathbf{3}$ into $\mathbf{8}$. For secocollinone detection and structural characterization by NMR, derivatization to $\mathbf{6}$ by dimethyl sulfate (DMS) was required (gray dashed box). b Formation of on-pathway intermediate $\mathbf{1 0}$ (black arrows) and shunt product $\mathbf{9}$ (gray arrows) from $\mathbf{8}$. GrhO1 boosts $\mathbf{1 0}$ formation, while $\mathbf{9}$ production is minimized (see Fig. 2). c Proposed GrhO6-catalyzed formation of $\mathbf{4}$ from 10/11. Presumably, $\mathbf{3}$ and $\mathbf{1 1}$ are largely skipped as intermediates in the reducing environment of the cell. Dashed arrows indicate autooxidation steps. Electron-dependent steps (indicated by $2[\mathrm{H}]$ ) require NADPH as preferred reductant for both GrhO5 and GrhO6, see text. The spiroketal-configuration of $\mathbf{1 1}$ (racemic) and $\mathbf{4}$ (chiral) were analyzed by CD spectroscopy, see text. All intermediates in boxes were characterized by NMR and/or HRMS. Note that the final product $\mathbf{4}$ spontaneously converts to 12 (see below).

spontaneous racemization via rapid ring-opening and recylization. Consistent with that, the racemate could not be separated by chiral HPLC (Supplementary Fig. 32).

GrhO6 completes formation of the mature [5,6]-spiroketal moiety. GrhO6 is also predicted to be a member of the class A flavoprotein monooxygenases and has $31.4 \%$ amino acid (aa) identity ( $70 \%$ sequence coverage) with GrhO5. The $\Delta g r h O 6$ mutant strain was previously shown to accumulate 11, suggesting a possible role for GrhO6 in spiroketal formation ${ }^{10}$. Hence, polyhistidinetagged GrhO6 was heterologously produced and isolated, which contained a tightly, but non-covalently bound FAD cofactor similar to GrhO5 (Supplementary Fig. 33). Indeed, upon complementing the GrhO5/GrhO1 assay with GrhO6, a stable main product 12 was formed in vitro (Fig. 2). LC-HRMS 2 and UV-Vis spectra suggested that $\mathbf{1 2}$ may represent a derivative of the anticipated final product 7,8-dideoxy-6-oxogriseorhodin $\mathrm{C}(4)$ with a mass of $\left[4+\mathrm{H}_{2} \mathrm{O}\right]$ (Supplementary Fig. 34).

To further investigate this, we cultured S. albus sp. J1074 KR7 $(\Delta g r h 07)$ for the production of 7,8-dideoxygriseorhodin C (13, Fig. 4) ${ }^{10}$. After confirmation of the authenticity of 13 by HRMS/MS ${ }^{2}$, and NMR (Supplementary Figs. 35-37), we chemically oxidized the secondary alcohol at C6 of 13 using DessMartin periodinane to generate 4 . In total, $20 \mathrm{mg}$ of 13 was oxidized to $15 \mathrm{mg}$ of 4 , as verified by HPLC, HRMS/MS ${ }^{2}$, and NMR (Supplementary Figs. 34a, 38a, and 39-42). Indeed, when 4 was dissolved in water and incubated at $\mathrm{pH} 2$ or $\mathrm{pH} 7$ with temperatures ranging from 4 to $50^{\circ} \mathrm{C}$, it was non-enzymatically converted to 12 in aqueous phase at neutral $\mathrm{pH}$ (i.e. enzyme assaylike conditions), while remaining largely stable under acidic conditions (Fig. 4 and Supplementary Fig. 43a). When this reaction was carried out in $\mathrm{H}_{2}{ }^{18} \mathrm{O}$, incorporation of ${ }^{18} \mathrm{O}$ was observed, suggesting that $\mathbf{1 2}$ represents a hydrate of $\mathbf{4}$ (Supplementary Fig. 43b). Moreover, upon scrutinizing our enzymatic assays, 4 could be detected (Supplementary Fig. 38b). Although NMR analysis of $\mathbf{1 2}$ proved inadequate to fully elucidate the structure and chemical derivatization also failed (Supplementary Figs. 44-47), infrared spectroscopy and density functional theory (DFT) computation (Supplementary Fig. 48) suggested that $\mathbf{4}$ undergoes spiroketal hydrolysis to yield 12, consistent with NMR, MS, and UV-Vis data (Supplementary Figs. 34, and 44-47). This exergonic reaction $\left(\Delta G^{\circ}=-5.1 \mathrm{~kJ} \mathrm{~mol}^{-1}\right.$ according to DFT calculations) is likely driven by the ring strain caused by the $\mathrm{sp}^{2}$ hybridized C6-ketone of $\mathbf{4}$ and proceeds via a transient ringopened oxocarbenium that is quenched by water to form 12 . Most likely, 4 represents the true GrhO6 product that rapidly converts to $\mathbf{1 2}$ when not further processed by downstream pathway enzymes (most likely by a $\mathbf{1 3}$-forming ketoreductase $\mathrm{e}^{10}$, Figs. 1 and 4).
To confirm that $\mathbf{1 1}$ is a substrate for GrhO6, the compound was purified and used for separate in vitro assays with GrhO6. Similar to GrhO5, GrhO6 first reduced 11 into $\mathbf{1 0}$ before forming $12 / 4$ in the presence of NADPH $(\approx 40 \%$ activity with NADH), as quantified by UV-Vis spectroscopy (see Supplementary Fig. 2 for kinetics) and further analyzed by RP-HPLC, whereas 9 was not accepted as substrate (Supplementary Fig. 49a, b). Moreover, the requirement for $\mathrm{NAD}(\mathrm{P}) \mathrm{H}$ suggested a monooxygenase functionality for GrhO6. This was further confirmed by ${ }^{18} \mathrm{O}_{2}$-labeling experiments, which revealed the incorporation of ${ }^{18} \mathrm{O}$ into the western molecule half (Supplementary Fig. 49c and Supplementary Table 6). GrhO6 likely employs a similar mechanism to GrhO5. Following NAD(P)H-dependent 10 formation, GrhO6 then likely catalyzes an aromatic hydroxylation at $\mathrm{C} 2$ of $\mathbf{1 0}$ (step XII, Fig. 3c), which dearomatizes ring B and affords a C3ketone in $\beta$-position to the $\mathrm{C} 1$-lactone moiety. This enables the subsequent decarboxylation of $\mathrm{C} 1$ via formation of a transient oxocarbenium that is quenched through intramolecular nucleophilic attack by the introduced C2-hydroxyl-group and thereby generates the $[5,6]$-spiroketal of 4 (Fig. 3c). CD spectroscopy verified the chirality of compound $\mathbf{4}$ that features the same configuration at the C6a as $\mathbf{1}^{10,25}$, suggesting that $[5,6]$-spiroketal formation is stereochemically controlled by GrhO6 (Supplementary Fig. 50).

Metabolomic and genomic analyses support a universal pathway for spiroketal formation in the rubromycin polyketide family. In contrast to $3,4,11$, the intermediates $5,7,8,9,10,12$ were hitherto uncharacterized. To verify the authenticity of some key pathway intermediates, we extracted liquid cultures at various time points during growth of S. albus sp. J1074 (heterologous 1 producer $)^{10}$, Actinoplanes ianthinogenes (native producer of purpuromycin ${ }^{26}$ ), and $S$. puniceus (native producer of 1 and griseorhodin C) ${ }^{25}$. RP-HPLC and LC-HRMS analysis clearly confirmed the presence of $\mathbf{1 0}$ (that likewise underwent spontaneous oxidation to 11) and 12 in various cell free lysates, while $\mathbf{5}$, unstable $\mathbf{8}$, and shunt product $\mathbf{9}$ were not observed. Also, 7 could not be directly detected as a result of the poor interaction with chromatographic stationary phases. However, complex compound mixtures including insoluble compounds prone to polymerization were previously reported (but not further characterized) in the $\Delta g r h O 1$ mutant strain $S$. albus J1074 KR5 $5^{10}$. Indeed, upon treatment of the cell free lysate of a culture of this strain with DMS, 6 could be obtained (Supplementary Fig. 9b).

Furthermore, genomic data suggest that the biosynthetic gene clusters for production of spiroketal-containing 1 (S. sp. JP95), 2 (of $S$. collinus) ${ }^{15}$, hyaluromycin (of S. hyaluromycini $\mathrm{MB}-\mathrm{PO} 13)^{27}$, and of heliquinomycin (S. piniterrae) ${ }^{28}$ harbor grhO5, grhO1, and grhO6 homologs (the genome of the 


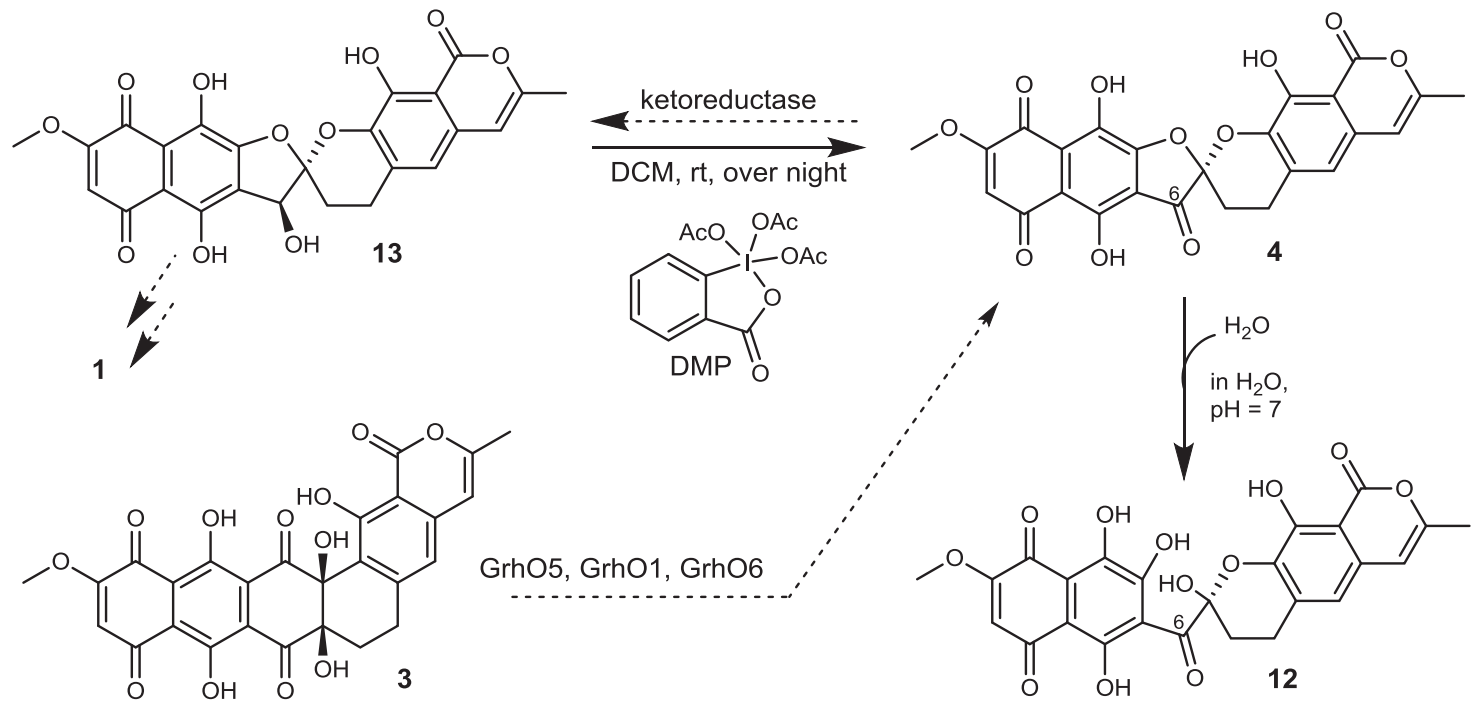

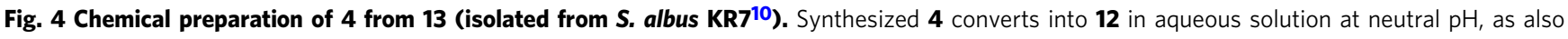
observed in the enzyme assays (Fig. 2). Note that the structure of $\mathbf{1 2}$ is supported by NMR and IR data, as well as DFT calculations, but a C6-ketohydrate instead of the shown ring-opened compound $\mathbf{1 2}$ cannot be ruled out (see Supplementary Fig. 48). Enzymatic steps are indicated with dashed arrows, nonenzymatic chemical steps with bold arrows. A ketoreductase may deter water addition in vivo en route to $\mathbf{1}$. The stereochemical configuration of $\mathbf{1 3}$ and $\mathbf{4} / \mathbf{1 2}$ is depicted as previously determined for $\mathbf{1}$ and verified in this work. DMP: Dess-Martin periodinane, DCM: dichloromethane.

Streptomyces sp. JP95 griseorhodin A biosynthetic gene cluster (AF509565)

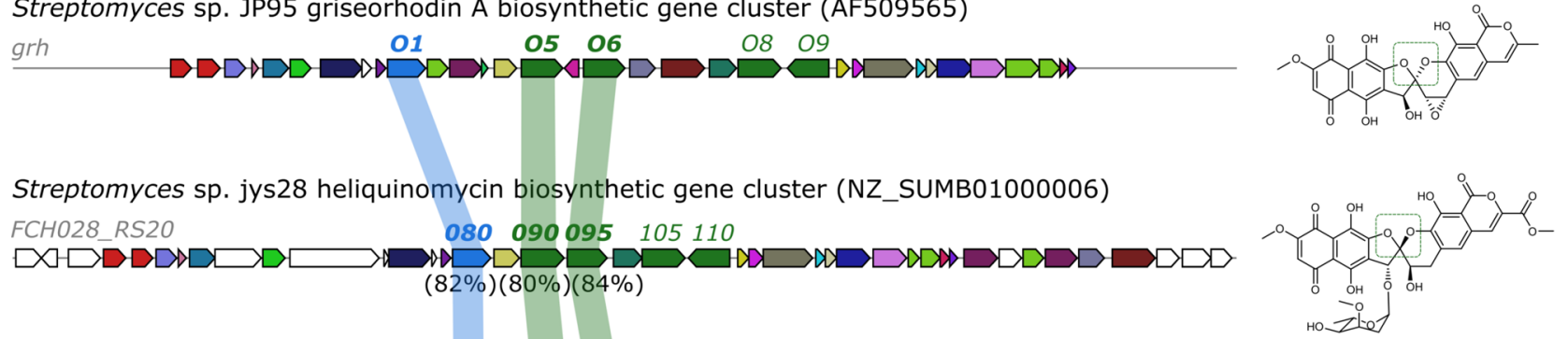

Streptomyces hyaluromycini hyaluromycin biosynthetic gene cluster (NZ_BCFL01000018)

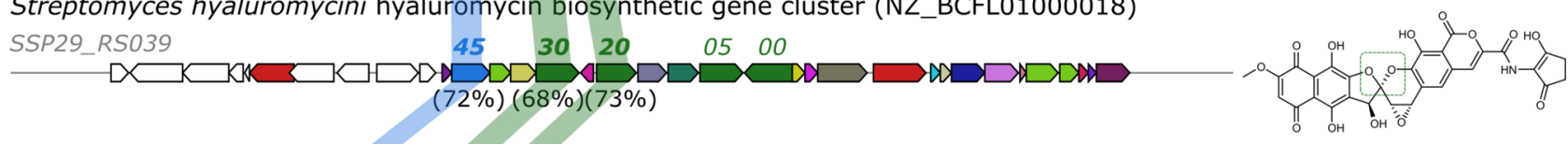

Streptomyces collinus DSM2012 rubromycin biosynthetic gene cluster (AF293355)

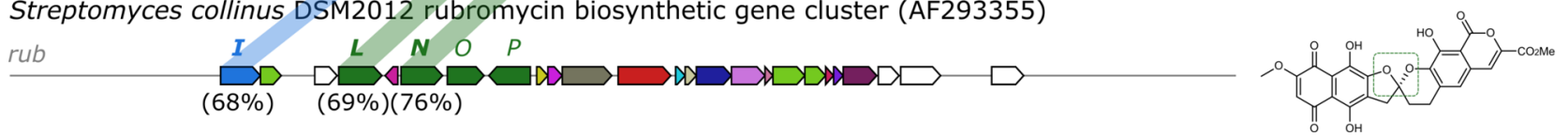

Fig. 5 Gene cluster comparison performed with MultiGeneBlast ${ }^{29}$. Same colors indicate high amino acid sequence similarities and predicted similar functions. The biosynthetic gene clusters for production of the spiroketal-containing compounds griseorhodin A (1, AF509565), heliquinomycin (NZ_SUMB01000006), hyaluromycin (NZ_BCFL01000018), and rubromycin (2, AF293355) are shown. These clusters harbor grhO5 (green), grh01 (blue), and grhO6 (green) homologs. Corresponding homologs are connected with a shadow and the percentages of the amino acid sequence identities of the encoded proteins are shown. The grhO8 and grh09 genes also show homology to grh05 and grhO6 and encode FAD-dependent monooxygenases involved in early redox tailoring steps. The biosynthetic gene clusters of the non-spiroketal pentangular polyketides lack grhO1, grhO5, and grhO6 gene candidates necessary for spiroketal formation (see Supplementary Fig. 51 for full comparison).

bacterial purpuromycin producer is not available yet). Compared to that, respective candidate genes were absent in the biosynthetic gene clusters of the non-spiroketal compounds benastatin A, fredericamycin A (featuring a carbaspirocycle), pradimicin A, lysolipin, and arixanthomycins (Fig. 5 and Supplementary Fig. 51). To further verify a common pathway for spiroketal formation in the rubromycin polyketide family, we acquired heterologously produced polyhistidine-tagged RubL - the predicted functional homolog of GrhO5 encoded by the rubromycin biosynthetic gene cluster - and showed that it catalyzed the virtual identical conversion of 3 into 10/11 (Supplementary Fig. 52).

\section{Discussion}

Ever since their discovery, rubromycin-type polyketides have sparked the interest of synthetic chemists and biochemists because of their complex framework and potent bioactivities. While spiroketal groups are occasionally encountered in natural products, adjacent aromatic rings giving rise to distinct bisbenzannulated 
spiroketals are exceedingly rare ${ }^{30}$. These spiroketals are remarkably robust owing to the stabilizing effect of the connected aryl functionalities through delocalization of the lone pairs of electrons from the oxygen atoms ${ }^{30}$. In this work, we provide detailed insights into the enzymology and biochemistry underlying the installment of the $[5,6]$-spiroketal pharmacophore into the backbone of rubromycin natural products. These redox tailoring processes are driven by the multifunctional spiroketalase GrhO5 (assisted by GrhO1) that produces key intermediate 10 , which is subsequently transformed by GrhO6 into 4. Both GrhO5 and GrhO6 resemble characterized class A flavoprotein monooxygenases, e.g., GrhO5 is related to the aromatic hydroxylase $\mathrm{RdmE}(40.7 \%$ aa identity, $100 \%$ coverage) from aklavinone biosynthesis ${ }^{31}$ and to $\mathrm{XanO} 4(42.3 \%$ aa identity, 98\% coverage) catalyzing oxygenation and demethoxylation in xanthone biosynthesis ${ }^{32}$. Moreover, GrhO5 resembles the predicted aromatic hydroxylases $\mathrm{GrhO} 8$ ( $45.5 \%$ aa identity, $98 \%$ coverage) and GrhO9 (44\% aa identity, 94\% coverage) from 1 biosynthesis that presumably catalyze early tailoring steps en route to $3^{10}$. On the other hand, GrhO6 is more closely related to aromatic hydroxylases such as OxyS (43.9\% aa identity, 94\% coverage) from oxytetracycline biosynthesis ${ }^{33}$ and verified BVMOs, e.g., MtmOIV (45\% aa identity, $92 \%$ coverage) from mithramycin biosynthesis ${ }^{34}$ (Supplementary Fig. 53).

Our results imply a reaction sequence for GrhO5 that combines versatile redox chemistry (quinone reduction, aromatic hydroxylation, and alcohol oxidation) with various non-redox steps (e.g., retro-aldol ring cleavage and spiroketalization). While flavoenzyme functionalities such as quinone reduction ${ }^{35}$, quinone reduction coupled to aromatic hydroxylation ${ }^{36}$, or alcohol oxidation $^{37}$ have been reported before, a single flavoenzyme that combines these steps and additionally drastically rearranges the carbon backbone is noteworthy. Notably, although initial substrate reduction is not common for flavoprotein monooxygenases ${ }^{22}$, it seems to be a more widely employed strategy in natural product biosynthesis for the activation of quinonic compounds prior to further redox transformations of the resulting hydroquinones or respective diketotautomers, e.g., in aflatoxin or actinorhodin polyketide biosynthesis ${ }^{36,38-40}$. In the case of GrhO5, however, the first reduction of ring $\mathrm{A}$ is distant from the actual hydroxylation site and serves a further purpose: it is the requisite for the conversion of $\mathbf{8}$ into 10 , as a quinonic ring $A$ would deter ring $B$ oxidation and thus lead to accumulation of shunt product 9 (Fig. 3b). The flavoprotein oxidase GrhO1 additionally counteracts 9 generation by catalyzing the selective oxidation of the hydroquinonic ring $B$ to the $p$-quinone and thereby redirecting the metabolic flow to formation of $\mathbf{1 0}$ (Fig. 3b). Presumably, oxidized intermediates such as $\mathbf{3}$ and $\mathbf{1 0}$ might be largely skipped in the reductive environment of the cell and the quinonereducing flavoenzyme functionality of $\mathrm{GrhO} 5$ and $\mathrm{GrhO} 6$ would thus be primarily required for the salvaging of autooxidation products.

Finally, spiroketal maturation is completed by flavoprotein monooxygenase GrhO6 that converts the [6,6]-spiroketal moiety into the mature [5,6]-spiroketal. Based on the nucleophilicity of C2 of substrate 10, an aromatic hydroxylation appears likely (an alternative carbonate-producing Baeyer-Villiger oxidation of the C1-lactone ${ }^{10}$ is conceivable, but chemically unfavorable ${ }^{37}$ ). This hydroxylation then enables the final fourth $\mathrm{C}-\mathrm{C}$ bond cleavage via decarboxylation, followed by recyclization to the [5,6]-spiroketal of 4 (Fig. 3c). Our combined data suggest a universal flavoenzyme-mediated pathway for spiroketal formation in the rubromycin polyketide family. Presumably, final tailoring steps on the molecular periphery of $\mathbf{4}$ then expedite the diversification of rubromycin polyketides. Notably, 4 readily formed ring-opened derivative $\mathbf{1 2}$ and it remains to be seen if this compound can be further converted or represents a dead-end product. Most likely, keto reduction is required to decrease ring-strain and prevent this non-enzymatic spiroketal-opening in vivo, consistent with the evident lack of mature rubromycins with C6-ketone functionalities.

The complex flavin enzymology underlying the formation of the rubromycin pharmacophore thus provides an astonishing solution for the generation of stable chroman spiroketals in nature. These complex redox transformations of a polycyclic, aromatic backbone starkly contrast with synthetic approaches (that rely on convergent syntheses in which the naphthazarin and isocoumarin moieties are separately generated and combined prior to spiroketal generation ${ }^{12}$ ) as well as biosynthetic strategies and precursor molecules. Conventional enzyme-dependent routes rely, e.g., on a dihydroxyketone motif allowing hemiketal formation and dehydrative cyclization to afford the $[6,6]$-spiroketal of the pesticide avermectin ${ }^{41}$. Similarly, the proposed cascade-like [5,6]-spiroketal formation in the generation of the polyether antibiotics such as lasalocid A and monensin requires a hydroxy-ketone-epoxide motif and proceeds via initial hemiketal formation followed by epoxide-dependent spiroketalization ${ }^{42}$. Moreover, a radical mechanism has been proposed in griseofulvin biosynthesis ${ }^{43}$. Compared to these straightforward pathways, precursor 3 lacks evident structural requisites and functionalities for spiroketal formation and instead the pentangular precursor undergoes an unanticipated series of oxidative backbone rearrangements. Other noteworthy examples of flavoenzyme-driven oxidative rearrangements in type II polyketide biosynthesis are found, e.g., in chartreusin ${ }^{44}$, xanthone ${ }^{32}$, and rishirilide ${ }^{45}$ biosynthesis. Interestingly, an alternative strategy to disrupt aromatic polyketide planarity is employed in enterocin biosynthesis ${ }^{18,46,47}$, where a single flavoprotein monooxygenase drastically rearranges a linear poly- $\beta$-ketone chain ${ }^{18,24,48,49}$ rather than the cyclized backbone. Aside from flavoenzymes, other types of multifunctional monooxygenases (e.g., cytochrome P450s and non-heme iron $\alpha$-ketoglutarate-dependent enzymes) have also been reported in natural product biosynthesis ${ }^{50}$.

Taken together, this study contributes to our understanding of the catalytic versatility of flavin-dependent enzymes in natural product biosynthesis and lays the foundations for future (chemo) enzymatic formation of novel rubromycin analogs and hybrid compounds. Our work illustrates a counterintuitive principle for the generation of structurally complex polyketide scaffolds and spiroketal pharmacophores.

\section{Methods}

\section{Gene cloning, heterologous production, and protein purification}

Gene cloning. The grhO5, grhO1, and grhO6 genes were amplified from the cosmid pMP $31^{9}$ containing the grh gene cluster (all oligonucleotide primers from SigmaAldrich are shown in Supplementary Table 7). The grhO5 gene was inserted between the NdeI and PstI sites of the expression vector pMAL-c5x-His (New England Biolabs), the grhO1 gene between the NcoI and EcoRI sites of the expression vector pHis $8^{51}$ and the grhO6 gene between the EcoRI and PstI sites of the expression vector pETDuet-1 (Novagen, Merck KGaA). The rubL gene was synthesized (codon optimized) and purchased already cloned between the NdeI and XhoI sites of the expression vector pET-16b (BioCat).

Heterologous production and purification of GrhO5. The recombinant pMal-c5xHis-grhO5 plasmid was transformed into E. coli BL21 (DE3) (Thermo Fisher Scientific). LB-medium was inoculated with the transformed strain and supplemented with $100 \mu \mathrm{g} / \mathrm{mL}$ ampicillin at $37^{\circ} \mathrm{C}$ overnight under shaking at $180 \mathrm{rpm}$. Then, $1 \mathrm{~L}$ of TB-medium with $100 \mu \mathrm{g} / \mathrm{mL}$ ampicillin was inoculated with $10 \mathrm{~mL}$ of the starter culture and grown to an $\mathrm{OD}_{600}$ of $0.5-0.6$. The culture was induced with a final concentration of $250 \mu \mathrm{M}$ IPTG and the cells were grown overnight at $18^{\circ} \mathrm{C}$ under shaking $(130 \mathrm{rpm})$. The cells were retrieved by centrifugation at $4000 \times g$ for $20 \mathrm{~min}$ at $4{ }^{\circ} \mathrm{C}$. Cell pellets were suspended in buffer A $(20 \mathrm{mM}$ Tris $\mathrm{pH} 7.4,200 \mathrm{mM}$ sodium chloride) with additional $1 \mathrm{mg} / \mathrm{mL}$ lysozyme and $1 \mathrm{mM}$ phenylmethylsulfonyl fluoride and then stirred for $30 \mathrm{~min}$ at $4{ }^{\circ} \mathrm{C}$. Then, the cells were lysed by sonication and the cell fragments removed by centrifugation at $18,000 \times g$ for $30 \mathrm{~min}$ at $4{ }^{\circ} \mathrm{C}$. The supernatant was filtered through a $0.45-\mu \mathrm{m}$ syringe filter and then loaded onto a $5-\mathrm{mL}$ MBPTrap HP Dextrin Sepharose ${ }^{\mathrm{TM}}$ column (GE Healthcare) connected to an FPLC system. Following a washing step with buffer A, bound mbp-tagged GrhO5 was eluted by a gradient ranging from $0 \%$ to $100 \%$ buffer B $(20 \mathrm{mM}$ Tris pH 7.4, $200 \mathrm{mM}$ sodium chloride, $10 \mathrm{mM}$ maltose) over 5 column volumes. GrhO5 was concentrated using a $30-\mathrm{kDa}$ MW cut-off MACROSEP spin column (Pall Cooperation) and 
subsequently desalted with a 5-mL HiTrap desalting column (GE Healthcare). The identity and purity of recombinant GrhO5 was analyzed by SDS-PAGE.

Heterologous production and purification of GrhO1. The recombinant $\mathrm{pHis8-grhO1}$ plasmid was transformed into E. coli Lemo21 (DE3). The production and purification was performed according to the procedure described above using kanamycin $(50 \mu \mathrm{g} / \mathrm{mL})$ and chloramphenicol $(30 \mu \mathrm{g} / \mathrm{mL})$ as antibiotics and $750 \mu \mathrm{M}$ L-rhamnose for optimized expression levels. A 5-mL HisTrap ${ }^{\mathrm{TM}} \mathrm{FF}$ crude column (GE Healthcare) was used for purification. Unbound protein was removed by washing with buffer A (50 mM Tris pH 7.1, $300 \mathrm{mM}$ sodium chloride, $20 \mathrm{mM}$ imidazole, $10 \%$ glycerol) and $0-6 \%$ buffer B $(50 \mathrm{mM}$ Tris $\mathrm{pH} 7.1,300 \mathrm{mM}$ sodium chloride, $500 \mathrm{mM}$ imidazole, $10 \%$ glycerol) over five column volumes and bound his-tagged protein was then eluted with $100 \%$ buffer B. The protein was concentrated using a 10-kDa MW cut-off MACROSEP spin column (Pall Cooperation) and then further purified by size exclusion chromatography with a HiLoad $16 / 600$ Superdex $200 \mathrm{pg}$ column (GE Healthcare) equilibrated with buffer A (50 mM Tris, pH 7.4, $300 \mathrm{mM}$ sodium chloride) and connected to a FPLC system. Finally, $10 \%(v / v)$ glycerol was added to the fractions containing GrhO1. The identity and purity of the eluted protein was confirmed by SDS-PAGE.

Heterologous production and purification of GrhO6. The recombinant pETDuet-1grhO6 plasmid was transformed into E. coli BL21 (DE3) (Thermo Fisher Scientific). The production and purification was performed according to the procedure described above with ampicillin $(100 \mu \mathrm{g} / \mathrm{mL})$ and the respective buffers (buffer A: $50 \mathrm{mM}$ Tris pH 7.1, $300 \mathrm{mM}$ sodium chloride, $20 \mathrm{mM}$ imidazole; buffer B: $50 \mathrm{mM}$ Tris pH 7.1, $300 \mathrm{mM}$ sodium chloride, $500 \mathrm{mM}$ imidazole).

Heterologous production and purification of RubL. The recombinant pET-16b-rubL (BioCat) was transformed into E. coli BL21 (DE3). The production and purification was performed according to the procedure described above with ampicillin $(100 \mu \mathrm{g} / \mathrm{mL}$ ) and the respective buffers (buffer A: $50 \mathrm{mM}$ Tris pH 7.4, $300 \mathrm{mM}$ sodium chloride, $10 \%$ glycerol; buffer B: $50 \mathrm{mM}$ Tris pH 7.4, $300 \mathrm{mM}$ sodium chloride, $500 \mathrm{mM}$ imidazole, $10 \%$ glycerol).

Collinone (3) production and purification. Spores of the S. albus grhO5 knock-out strain were inoculated into $50 \mathrm{~mL}$ of TSB medium supplemented with apramycin $(50 \mu \mathrm{g} / \mathrm{mL})$ and grown at $30^{\circ} \mathrm{C}, 200 \mathrm{rpm}$ for $24 \mathrm{~h}$. The resulting culture was used to inoculate $3 \mathrm{~L}$ of TSB medium distributed to $1 \mathrm{~L}$ flasks with stainless-steel springs. Each flask contained $300 \mathrm{~mL}$ of culture supplemented with apramycin $(50 \mu \mathrm{g} / \mathrm{mL})$ and was incubated at $30^{\circ} \mathrm{C}, 200 \mathrm{rpm}$ for 4 days. The cells were harvested by centrifugation and the pellet was suspended in $\mathrm{dH}_{2} \mathrm{O}(300 \mathrm{~mL})$. The pellet/water solution was acidified to $\mathrm{pH} 1$ with $2 \mathrm{~N} \mathrm{HCl}, \mathrm{EtOAc}(500 \mathrm{~mL})$ was added and the mixture then stirred overnight. The supernatant was also acidified to $\mathrm{pH} 1$ with $2 \mathrm{~N} \mathrm{HCl}$ and extracted with EtOAc $(3 \times 500 \mathrm{~mL}$ for $1 \mathrm{~L}$ culture). The combined extracts of the supernatant were purified by column chromatography $\left[\mathrm{SiO}_{2}, \mathrm{CH}_{2} \mathrm{Cl}_{2} / \mathrm{MeOH}=9: 1(v / v)\right]$. Fractions containing 3 (detected via thin layer chromatography (TLC)) were combined, dried, and further purified by semi-preparative HPLC. The extract of the pellet fraction was directly purified by semi-preparative HPLC. An average of $10 \mathrm{mg} / \mathrm{L}$ cell culture of $\mathbf{3}$ was obtained. The purity of the red solid $\mathbf{3}$ was confirmed by highresolution liquid chromatography mass spectrometry (LC-HRMS) and 1D NMR analysis. The acquired NMR data are in accordance with previously published data $^{2,15}$. TLC $\left(\mathrm{CH}_{2} \mathrm{Cl}_{2}: \mathrm{MeOH}, 9: 1 v / v\right): R_{\mathrm{f}}=0.59 ; \mathrm{UV} / \mathrm{Vis}\left(\mathrm{CH}_{3} \mathrm{CN} / \mathrm{H}_{2} \mathrm{O}\right): \lambda 244,340$, $518 \mathrm{~nm}$; HRMS $(\mathrm{m} / \mathrm{z})$ : $[\mathrm{M}+\mathrm{H}]^{+}$calcd. for $\mathrm{C}_{27} \mathrm{H}_{18} \mathrm{O}_{12}, 535.087$; found, 535.088.

Lenticulone (11) production in S. albus KR42. Spores of the S. albus KR42 strain were inoculated into $50 \mathrm{~mL}$ of LB medium supplemented with apramycin $(50 \mu \mathrm{g} / \mathrm{mL})$ and grown at $30^{\circ} \mathrm{C}, 200 \mathrm{rpm}$ for 4 days. The cells were harvested by centrifugation and the supernatant was acidified to $\mathrm{pH} 3$ with $2 \mathrm{~N} \mathrm{HCl}$ and extracted with EtOAc $(2 \times$ $100 \mathrm{~mL}$ ). The solvent of the combined extracts was removed under reduced pressure and the residue dissolved in $\mathrm{CH}_{3} \mathrm{CN}$ and EtOAc. After centrifugation for $10 \mathrm{~min}$ at $18,000 \times g$, samples were analyzed by HPLC using a NUCLEODUR 100-5 C18ec column (varioprep, $250 \mathrm{~mm} \times 10 \mathrm{~mm}$ ID, $5 \mu \mathrm{M}$, Macherey-Nagel) coupled with a UNIVERSAL RP guard column $(4 \mathrm{~mm} \times 3 \mathrm{~mm}$ ID, Macherey-Nagel $)$.

Photometric assays for kinetic parameters of $\mathrm{GrhO} 5$ and GrhO6. The kinetic parameters for GrhO5 and GrhO6 were determined photometrically at wavelengths of 556 for collinone (3) and and $536 \mathrm{~nm}$ for lenticulone (11) using a Shimadzu Photometer (UV-1650PC, Shimadzu, Duisburg, Germany). A mixture of $50 \mathrm{mM}$ Tris pH 7.4, 1.5 mM NADPH or NADH and substrate $(16,39,79,392 \mu$ M collinone (3) or 20,50 , $100 \mu \mathrm{M}$ lenticulone (11), both dissolved in $\mathrm{CH}_{3} \mathrm{CN}$ ) was prepared. The reaction was started by addition of $1 \mu \mathrm{M}$ GrhO5 or GrhO6 (or free FAD as control) that allowed the measurement of the linear decrease in absorption. The turnover rates were calculated based on extinction coefficients of $4850 \mathrm{~L} \times \mathrm{mol}^{-1} \times \mathrm{cm}^{-1}$ at $556 \mathrm{~nm}(3)$ and $1700 \mathrm{~L} \times \mathrm{mol}^{-1} \times \mathrm{cm}^{-1}$ at $536 \mathrm{~nm}$ (11) according to Beer-Lambert law. The slope of the absorption was read out by the software (UV Probe 2.43, Shimadzu).

Standard assay with collinone (3) and GrhO5 (or RubL). A mixture of $50 \mathrm{mM}$ Tris $\mathrm{pH} 7.4,1.5 \mathrm{mM}$ NADH and NADPH, $10 \mu \mathrm{M}$ GrhO5, and $1 \%(v / v)$ hydroxypropylbeta-cyclodextrin (HPCD) was prepared. The reaction was started by addition of collinone $\left(0.25 \mathrm{mM}\right.$, dissolved in $\mathrm{CH}_{3} \mathrm{CN}$, final conc. of $\left.2.5 \%(v / v)\right)$ before incubation for $0.5-8 \mathrm{~min}$ at $30{ }^{\circ} \mathrm{C}$ while shaking at $750 \mathrm{rpm}$. The reaction was terminated by addition of EtOAc/formic acid [9:1 $(v / v)]$ and extracted by vigorous shaking. The mixture was centrifuged for $30 \mathrm{~s}$ and the layers then separated. The solvent was removed under reduced pressure and the compounds dissolved in $\mathrm{CH}_{3} \mathrm{CN}(20 \mu \mathrm{L})$ and EtOAc $(20 \mu \mathrm{l})$. After centrifugation for $10 \mathrm{~min}$ at $18,000 \times \mathrm{g}$, samples were analyzed by HPLC using a NUCLEODUR 100-5 C18ec column (varioprep, $250 \mathrm{~mm} \times 10 \mathrm{~mm}$ ID, $5 \mu \mathrm{M}$, Macherey-Nagel) coupled with a UNIVERSAL RP guard column $(4 \mathrm{~mm} \times 3 \mathrm{~mm}$ ID, Macherey-Nagel). The assay was also performed using identical conditions with RubL instead of GrhO5.

Enzymatic assay with GrhO5, GrhO1, and GrhO6. The enzyme assay was performed identical to the standard GrhO5 assay with additional $10 \mu \mathrm{M}$ of GrhO6 and/or $5 \mu \mathrm{M}$ of GrhO1. Reactions were quenched after $8 \mathrm{~min}$ and analyzed as described above.

Enzymatic assay to isolate dihydrocollinone (5). The enzymatic assay was performed under anaerobic conditions using the above described assay composition. The reaction was started in an anaerobic chamber by adding solution A ( $50 \mathrm{mM}$ Tris, 1 $\mu \mathrm{M}$ GrhO5, $1 \%(v / v)$ HPCD and collinone $\left(0.25 \mathrm{mM}\right.$, dissolved in $\mathrm{CH}_{3} \mathrm{CN}$, final conc. of $2.5 \%(v / v))$ to solution B (10\% glycerol, $1.5 \mathrm{mM} \mathrm{NADH}$ and NADPH). After $1 \mathrm{~min}$ the reaction mixture was extracted [EtOAc/formic acid $=9: 1(v / v)$ ] inside the anaerobic chamber. The mixture was centrifuged for $30 \mathrm{~s}$ and the layers then separated inside the anaerobic chamber. The next steps were performed under minimal exposure to $\mathrm{O}_{2}$. The solvent was removed under reduced pressure and the residue dissolved in $\mathrm{CH}_{3} \mathrm{CN}$ and EtOAc. After centrifugation for $10 \mathrm{~min}$ at $18,000 \times g$, compound 5 was purified by HPLC using a NUCLEODUR 100-5 C18ec column (varioprep, $250 \mathrm{~mm} \times 10 \mathrm{~mm} \mathrm{ID}, 5 \mu \mathrm{M}$, Macherey-Nagel) coupled with a UNIVERSAL RP guard column $(4 \mathrm{~mm} \times 3 \mathrm{~mm}$ ID, Macherey-Nagel). The yield of 5 was $\sim 12 \mathrm{mg}$ of orange solid. The product was analysed by ${ }^{1} \mathrm{H},{ }^{13} \mathrm{C}, 2 \mathrm{D}$ NMR, UV/Vis and ESI-HRMS. ${ }^{1} \mathrm{H}$ NMR $\left(600 \mathrm{MHz}, \mathrm{CDCl}_{3}\right): \delta 2.07-2.11(\mathrm{~m}, 1 \mathrm{H})$, 2.18-2.21 (m, 1H), $2.30(\mathrm{~s}, 3 \mathrm{H}), 2.92-2.96(\mathrm{~m}, 1 \mathrm{H}), 3.33-3.39(\mathrm{~m}, 1 \mathrm{H}), 3.61$ (brs, 1H), $4.00(\mathrm{~s}, 3 \mathrm{H}), 6.24(\mathrm{~s}, 1 \mathrm{H}), 6.35(\mathrm{brs}, 1 \mathrm{H}), 6.73(\mathrm{~s}, 1 \mathrm{H}), 6.88(\mathrm{~s}, 1 \mathrm{H})$, $9.55(\mathrm{~s}, 1 \mathrm{H}), 9.89(\mathrm{~s}, 1 \mathrm{H}), 12.29(\mathrm{~s}, 1 \mathrm{H}), 14.68(\mathrm{brs}, 1 \mathrm{H}), 15.48(\mathrm{~s}, 1 \mathrm{H}) . ;{ }^{13} \mathrm{C}$ NMR $\left(150 \mathrm{MHz}, \mathrm{CDCl}_{3}\right): \delta 19.4,26.1,29.1,56.5,76.6,80.1,100.6,102.8,103.8,104.2$, 104.6, 107.5, 114.9, 115.7, 117.7, 137.3, 141.0, 147.4, 152.2, 154.0, 154.9, 160.4, 161.4, 162.7, 167.0, 196.0, 197.1; UV/Vis $\left(\mathrm{CH}_{3} \mathrm{CN} / \mathrm{H}_{2} \mathrm{O}\right): \lambda 259,338,455,481 \mathrm{~nm}$; and HRMS (m/z): $[\mathrm{M}-\mathrm{H}]^{-}$calcd. for $\mathrm{C}_{27} \mathrm{H}_{20} \mathrm{O}_{12}, 535.088$; found, 535.088 .

Enzymatic assays with compound 9. A solution of $50 \mathrm{mM}$ Tris $\mathrm{pH} 7.4,1.5 \mathrm{mM}$ $\mathrm{NADH} / \mathrm{NADPH}, 10 \mu \mathrm{M}$ of either GrhO5, GrhO1 or GrhO6, and $1 \%(v / v) \mathrm{HPCD})$ was prepared. The reaction was started by addition of compound $\mathbf{9}$ (dissolved in $\mathrm{CH}_{3} \mathrm{CN}$, final conc. of $2.5 \%(v / v) \mathrm{CH}_{3} \mathrm{CN}$ in assay) before incubation for $5 \mathrm{~min}$ at $30^{\circ} \mathrm{C}$ while shaking at $750 \mathrm{rpm}$. The reaction was quenched by addition of EtOAc/ formic acid $[9: 1(v / v)]$ and extracted by vigorous shaking. The mixture was centrifuged for $30 \mathrm{~s}$ and the layers then separated. The solvents were removed under reduced pressure and the compounds dissolved in $\mathrm{CH}_{3} \mathrm{CN}(20 \mu \mathrm{l})$ and EtOAc $(20 \mu \mathrm{l})$. After centrifugation for $10 \mathrm{~min}$ at $18,000 \times g$, samples were analyzed by HPLC.

Enzymatic assay to isolate compound 9 and compound characterization. A large scale enzyme assay ( $200 \mathrm{~mL}$ distributed to Eppendorf tubes each containing $500 \mu \mathrm{L}$ ) was performed using the same composition of constituents as described for the standard GrhO5 assay. The reaction was quenched after $15 \mathrm{~min}$ and compound 9 purified as described above for $\mathbf{5}$ but under aerobic conditions. The yield of $\mathbf{9}$ was $\sim 2 \mathrm{mg}$ of red solid. The product was analysed by ${ }^{1} \mathrm{H},{ }^{13} \mathrm{C}, 2 \mathrm{D}$ NMR, UV/Vis, and ESI-HRMS. ${ }^{1} \mathrm{H}$ NMR (400 MHz, DMSO-d $\mathrm{d}_{6}$ 1\% TFA-d): $\delta 2.04-2.08$ (m, 2H), 2.15 (s, 3H), 2.61-2.65 $(\mathrm{m}, 2 \mathrm{H}), 3.96(\mathrm{~s}, 3 \mathrm{H}), 6.33(\mathrm{~s}, 1 \mathrm{H}), 6.55(\mathrm{~s}, 1 \mathrm{H}), 6.57(\mathrm{~s}, 1 \mathrm{H}), 10.71$ (brs, $1 \mathrm{H}), 12.13$ (brs, $1 \mathrm{H}), 13.01(\mathrm{~s}, 1 \mathrm{H}){ }^{1}{ }^{\mathrm{H}}$ NMR $\left(400 \mathrm{MHz}, 1,4\right.$-dioxane- $\left.\mathrm{d}_{8}\right): \delta 2.10-2.16(\mathrm{~m}, 5 \mathrm{H}), 2.73-2.78$ $(\mathrm{m}, 2 \mathrm{H}), 3.94(\mathrm{~s}, 3 \mathrm{H}), 5.24(\mathrm{brs}, 1 \mathrm{H}), 6.13(\mathrm{~s}, 1 \mathrm{H}), 6.39(\mathrm{~s}, 1 \mathrm{H}), 6.55(\mathrm{~s}, 1 \mathrm{H}), 8.10$ (brs 1H), 10.82 (brs, $1 \mathrm{H}), 12.92$ (brs, $1 \mathrm{H}) ;{ }^{13} \mathrm{C}$ NMR (100 MHz, DMSO-d $\mathrm{d}_{6}, 1 \%$ TFA-d) $\delta$ 18.6, 24.3, 33.7, 57.6, 76.9, 103.9, 103.9, 104.2, 110.7, 116.1, 118.4, 128.3, 128.3, 137.4, 141.7, 141.7, 147.3, 147.3, 151.2, 151.2, 161.5, 166.1, 166.1, 183.1, 190.0, 197.9; Most signals are unambiguously assigned, also due to HSQC and HMBC signals. Some signals of quaternary carbon atoms are extraordinarily strong because of the complete overlap of two carbons. The signals in italics show the carbon atoms with lacking HSQC and HMBC signals that are assigned due to chemical shifts observed for biosynthetically related molecules (see Supplementary Figs. 20-24); Notably, the proton attached to C13 could not be detected in DMSO- $\mathrm{d}_{6}$, possibly because of a proton exchange with the adjacent carboxyl group or interaction with metals that is often observed for such compounds. However, the measurement in 1,4-dioxane- $\mathrm{d}_{8}$ revealed the proton attached to $\mathrm{C} 13$ and HRMS as well as extensive MS/MS fragmentation including ${ }^{18} \mathrm{O}$ labeled fragments (in particular the diagnostic unlabeled 319 and labeled 321 fragments) strongly support the proposed structure (see Supplementary Figs. 25-27 and Supplementary Table 1-3 for fragmentation). UV/Vis $\left(\mathrm{CH}_{3} \mathrm{CN} / \mathrm{H}_{2} \mathrm{O}\right): \lambda 232,364,503 \mathrm{~nm}$; HRMS $(m / z):[\mathrm{M}+\mathrm{H}]^{+}$calcd. for $\mathrm{C}_{26} \mathrm{H}_{18} \mathrm{O}_{12}, 523.087$; found, 523.089.

Standard assay with lenticulone (11) and GrhO6. A solution of $50 \mathrm{mM}$ Tris $\mathrm{pH} 7.4$, $1.5 \mathrm{mM}$ NADH and/or NADPH, $10 \mu \mathrm{M}$ GrhO6, and $1 \%(v / v)$ HPCD was prepared The reaction was started by addition of lenticulone (dissolved in $\mathrm{CH}_{3} \mathrm{CN}$, final conc. of $2.5 \%(v / v) \mathrm{CH}_{3} \mathrm{CN}$ in assay) before incubation for $30 \mathrm{~min}$ at $30{ }^{\circ} \mathrm{C}$ while 
shaking at $750 \mathrm{rpm}$. The reaction was quenched by addition of EtOAc/formic acid $[9: 1(v / v)]$ and extracted by vigorous shaking. The mixture was centrifuged for $30 \mathrm{~s}$ and the layers then separated. The solvents were removed under reduced pressure and the compounds dissolved in $\mathrm{CH}_{3} \mathrm{CN}(20 \mu \mathrm{l})$ and EtOAc $(20 \mu \mathrm{l})$. After centrifugation for $10 \mathrm{~min}$ at $18,000 \times \mathrm{g}$, samples were analyzed by HPLC.

Enzymatic assay to isolate lenticulone (11) and compound characterization. The large scale enzyme assay $(75 \mathrm{~mL}$ distributed to Eppendorf tubes each containing $1 \mathrm{~mL}$ ) was performed using the same composition of constituents as described for the standard GrhO5 assay with additional $5 \mu \mathrm{M}$ of GrhO1. The reaction was quenched after $10 \mathrm{~min}$ and 10/11 were isolated as described above for 5 but under aerobic conditions (collected compound $\mathbf{1 0}$ subsequently autooxidized to 11 ). The yield of 11 was $\sim 1.1 \mathrm{mg}$ of red solid. The product was analysed by ${ }^{1} \mathrm{H},{ }^{13} \mathrm{C}$ NMR, UV/Vis, and ESI-HRMS. The acquired NMR data are in accordance with previously published data ${ }^{10}$. UV/Vis $\left(\mathrm{CH}_{3} \mathrm{CN} / \mathrm{H}_{2} \mathrm{O}\right): \lambda 233,354,496 \mathrm{~nm}$; HRMS $(\mathrm{m} / z):[\mathrm{M}+\mathrm{H}]^{+}$calcd. for $\mathrm{C}_{26} \mathrm{H}_{16} \mathrm{O}_{12}, 521.072$; found, 521.070.

Reduction of lenticulone (11). The enzymatic assay was performed under anaerobic conditions. The reaction was started in an anaerobic chamber by adding solution $\mathrm{A}$ (50 mM Tris pH 7.4, $1.5 \mathrm{mM}$ NADH and/or NADPH, $5 \mu \mathrm{M}$ GrhO5 or GrhO6 or $1 \mathrm{mM} \mathrm{Ti}(\mathrm{III})$ citrate and $1 \%(v / v)$ HPCD) to solution B (10\% glycerol, NADH and $\mathrm{NADPH})$. After $1 \mathrm{~min}$ the reaction mixture was extracted [EtOAc/formic acid $=$ $9: 1(v / v)]$, the layers separated and the mixture analyzed on a photometer inside the anaerobic chamber.

${ }^{18} \mathrm{O}$-labeling assays with GrhO5. The dioxygen in solution A (Tris pH 7.4, $50 \mathrm{mM}$, $10 \mu \mathrm{M}$ GrhO5, and $1.5 \mathrm{mM}$ NADH and NADPH) and solution B $(0.5 \mathrm{mM}$ compound 3, $1 \%(v / v)$ HPCD and $10 \%$ glycerol) was thoroughly removed by 10 cycles of treatment with vacuum and nitrogen gas. Solution $\mathrm{B}$ was added to solution A in an anaerobic chamber and the reaction was started by injection of about $97 \%{ }^{18} \mathrm{O}_{2}$ gas (Campro Scientific). The reaction was stirred at room temperature for 1 and $5 \mathrm{~min}$ and then extracted [EtOAc/formic acid $=9: 1(v / v)]$. The solvent was removed under reduced pressure and the residue dissolved in $\mathrm{CH}_{3} \mathrm{CN}(20 \mu \mathrm{l})$ and EtOAc $(20 \mu \mathrm{l})$ before LC-HRMS analysis. The assays with $\mathrm{H}_{2}{ }^{18} \mathrm{O}$ were performed corresponding to typical GrhO5 assays with at least 55\% of labeled water in the reaction mixture.

Secocollinone (7) derivatization via methylation and compound characterization. $S$. albus KR5 spores were inoculated into $100 \mathrm{~mL}$ of TSB medium and grown overnight. The resulting seed culture was used to inoculate $9 \mathrm{~L}$ of TSB medium, which was distributed to thirty $1 \mathrm{~L}$ baffled flasks with stainless-steel springs. Flasks were incubated at $200 \mathrm{rpm}$ for 4 days at $30^{\circ} \mathrm{C}$. The cells were harvested by centrifugation and resuspended in $\mathrm{H}_{2} \mathrm{O}(500 \mathrm{~mL})$ with trifluoroacetic acid $(0.1 \% \mathrm{TFA}$; at $\mathrm{pH} 3)$. EtOAc ( $1 \mathrm{~L})$ was added and the solution was stirred overnight at room temperature. After centrifugation, the layers were separated and the solvent of the organic layer was removed under reduced pressure. In total, $1.4 \mathrm{~g}$ crude extract was obtained from $9 \mathrm{~L}$ of culture. To a suspension of crude extract ( $1.4 \mathrm{~g})$ of $S$. albus KR5 and anhydrous $\mathrm{K}_{2} \mathrm{CO}_{3}(15 \mathrm{~g}, 108.5 \mathrm{mmol})$ in dry acetone $(150 \mathrm{~mL})$, dimethyl sulfate (DMS) $(17 \mathrm{~mL}, 22.6 \mathrm{~g}, 179.3 \mathrm{mmol})$ was added dropwise. The mixture was stirred at room temperature for $1 \mathrm{~h}$ and then heated under reflux for $20 \mathrm{~h}$ at $40^{\circ} \mathrm{C}$. Afterwards, the mixture was cooled to room temperature and diluted with $\mathrm{H}_{2} \mathrm{O}(300 \mathrm{~mL})$. After stirring for additional $30 \mathrm{~min}$, the mixture was extracted with EtOAc $(500 \mathrm{~mL})$. The layers were separated and the organic layer was washed with water. The solvent was removed under reduced pressure. The remaining extract was purified by column chromatography $\left[\mathrm{SiO}_{2}, \mathrm{CH}_{2} \mathrm{Cl}_{2} / \mathrm{EtOAc}=1: 1(v / v)\right]$. Fractions containing 6 (detected via TLC) were combined, dried, and further purified by semi-preparative HPLC. After a second purification step, the isolated yield was $4 \mathrm{mg}$ of a yellow solid. The purity of $\mathbf{6}$ was confirmed by LC-HRMS and NMR analysis. TLC $\left(\mathrm{CH}_{2} \mathrm{Cl}_{2} / \mathrm{EtOAc}\right.$, $1: 1 v / v): R_{\mathrm{f}}=0.42 ;{ }^{1} \mathrm{H}$ NMR $\left(600 \mathrm{MHz}, \mathrm{DMSO}-\mathrm{d}_{6}\right): \delta 2.16(\mathrm{~s}, 3 \mathrm{H}), 2.83-2.85(\mathrm{~m}$, 2H), 2.90-2.91 (m, 2H), $3.79(\mathrm{~s}, 3 \mathrm{H}), 3.79(\mathrm{~s}, 3 \mathrm{H}), 3.81(\mathrm{~s}, 6 \mathrm{H}), 3.87$ (s, 3H), 3.88 (s, 3H), $3.91(\mathrm{~s}, 3 \mathrm{H}), 3.97(\mathrm{~s}, 3 \mathrm{H}), 6.40(\mathrm{~s}, 1 \mathrm{H}), 7.01(\mathrm{~s}, 1 \mathrm{H}), 7.06(\mathrm{~s}, 1 \mathrm{H}) ;{ }^{13} \mathrm{C}$ NMR $\left(150 \mathrm{MHz}\right.$, DMSO-d $\left.\mathrm{d}_{6}\right): \delta 19.3,25.6,31.1,56.9,57.1,61.5,61.5,61.6,62.0,62.0,63.1$, $102.7,103.2,112.5,115.6,121.9,124.8,128.8,130.4,135.4,135.8,140.4,144.4,147.4$, $151.0,153.9,153.9,154.4,156.2,156.4,158.5,158.6,180.7,183.6$; UV/Vis $\left(\mathrm{CH}_{3} \mathrm{CN} /\right.$ $\left.\mathrm{H}_{2} \mathrm{O}\right): \lambda$ 231, 265, 350, $396 \mathrm{~nm}$; HRMS $(m / z):[\mathrm{M}+\mathrm{H}]^{+}$calcd. for $\mathrm{C}_{34} \mathrm{H}_{34} \mathrm{O}_{12}$, 635.212; found, 635.214. The methylation of 7 in the course of enzymatic assays with GrhO5 was performed analogously in smaller scale and analyzed by HPLC as described for the standard assays with GrhO5.

7,8-dideoxygriseorhodin $C$ (13) and compound characterization. S. albus KR7 spores $(50 \mu \mathrm{L})$ were inoculated into $50 \mathrm{~mL} \mathrm{LB}$ medium and grown at $30^{\circ} \mathrm{C}, 200 \mathrm{rpm}$ for $24 \mathrm{~h} .5 \mathrm{~mL}$ of the starter culture was transferred into 10 flasks containing $300 \mathrm{~mL}$ $\mathrm{LB}$ medium and cultivation was continued at $30^{\circ} \mathrm{C}, 200 \mathrm{rpm}$ for $96 \mathrm{~h}$. This procedure was repeated four times resulting in a total culture volume of $12 \mathrm{~L}$. After cell harvesting by centrifugation $\left(60 \mathrm{~min}, 4000 \times g, 4^{\circ} \mathrm{C}\right)$ the supernatant was separated from the pellet and the pellet was resupended in $\mathrm{H}_{2} \mathrm{O}(4 \times 500 \mathrm{~mL})$. Pellet suspensions were acidified with $\mathrm{HCl}(6 \mathrm{M}, 20 \mathrm{~mL})$ in $500 \mathrm{~mL}$ portions. EtOAc $(2 \times$ $500 \mathrm{~mL}$ ) was added and the mixture was stirred overnight. The combined organic layers were concentrated under reduced pressure and the residue subjected to a short silica column [ $\mathrm{SiO} 2, \mathrm{CH} 2 \mathrm{Cl} 2 / \mathrm{MeOH} / \mathrm{AcOH}=95: 5: 0.1]$. Fractions containing compound 13 were combined. Solvents were removed under reduced pressure and further purified via semi-preparative HPLC, which yielded $120 \mathrm{mg}$ of red solid from the pellet. The supernatant was acidified with conc. $\mathrm{HCl}(10 \mathrm{~mL} / \mathrm{L})$ and extracted with EtOAc $(1 \mathrm{~L}$ culture with $2 \times 500 \mathrm{~mL}$ ). The combined organic layers were filtered and evaporated under reduced pressure yielding $2.60 \mathrm{~g}$ of crude extract from the supernatant. Further purification was performed by column chromatography [SiO2, $\mathrm{CH}_{2} \mathrm{Cl}_{2} / \mathrm{MeOH} / \mathrm{AcOH}=98: 2: 0.1(v / v)(2 \mathrm{~L})$, then $\mathrm{CH}_{2} \mathrm{Cl}_{2} /$ $\mathrm{MeOH} / \mathrm{AcOH}=95: 5: 0.1(v / v)]$ and provided $750 \mathrm{mg}$ of crude product. The crude product was further purified via semi-preparative HPLC. Solvents were removed under reduced pressure yielding again $11.6 \mathrm{mg}$ of red solid isolated from the supernatant. The overall yield was $131.6 \mathrm{mg}$ of red solid compound 13 . The product was analysed by ${ }^{1} \mathrm{H},{ }^{13} \mathrm{C}$ NMR, UV/Vis and ESI-HRMS. The acquired NMR data are in accordance with previously published data ${ }^{52}$. TLC $\left(\mathrm{CH}_{2} \mathrm{Cl}_{2} / \mathrm{MeOH} /\right.$ AcOH, 98:2:0.1 v/v): $R_{\mathrm{f}}=0.26$; UV/Vis $\left(\mathrm{CH}_{3} \mathrm{CN} / \mathrm{H}_{2} \mathrm{O}\right): \lambda 233,316,354,505 \mathrm{~nm}$; HRMS (m/z): $[\mathrm{M}+\mathrm{H}]^{+}$calcd. for $\mathrm{C}_{25} \mathrm{H}_{18} \mathrm{O}_{11}, 495.092$; found, 495.092

7,8-dideoxy-6-oxo-griseorhodin $C$ (4) and compound characterization. Dideoxygriseorhodin C (13) $(20.0 \mathrm{mg}, 40.5 \mu \mathrm{mol})$ was dissolved in dichloromethane (100 $\mathrm{mL})$ by vigorously stirring for $1 \mathrm{~h}$. DMP solution $(0.3 \mathrm{M}, \mathrm{DCM})(660 \mu \mathrm{L}, 198 \mu \mathrm{mol}$, $4.89 \mathrm{eq}$ ) was added and the reaction mixture was stirred at room temperature for $24 \mathrm{~h}$. The solvent was removed under reduced pressure at room temperature and the residue dissolved in $\mathrm{CH}_{3} \mathrm{CN}(100 \mu \mathrm{L})$. After centrifugation $(10 \mathrm{~min}, 18,000 \times g$, $\left.4{ }^{\circ} \mathrm{C}\right), \mathbf{4}$ was isolated by semi-preparative HPLC. The collected compound $\mathbf{4}$ was directly frozen in liquid nitrogen and solvents were removed by subsequent lyophilization for at least $24 \mathrm{~h}$ yielding $15 \mathrm{mg}$ of $4(30.5 \mu \mathrm{mol}, 75 \%)$ as dark purple solid. The product was analysed by NMR, UV/Vis and ESI-HRMS. The acquired NMR data are in accordance with previously published data ${ }^{53}$. TLC $\left(\mathrm{CHCl}_{3} /\right.$ $\mathrm{MeOH} / \mathrm{AcOH}, 95: 5: 0.1): R_{\mathrm{f}}=0.40$; UV/Vis $\left(\mathrm{CH}_{3} \mathrm{CN} / \mathrm{H}_{2} \mathrm{O}\right) \lambda 232,255,317,352$, $508 \mathrm{~nm}$; HRMS (m/z): $[\mathrm{M}+\mathrm{H}]^{+}$calcd. for $\mathrm{C}_{25} \mathrm{H}_{16} \mathrm{O}_{11} 493.077$, found 493.077.

Conversion of compound 4 into 12. A solution of $50 \mathrm{mM}$ Tris $\mathrm{pH} 7.4,7,8$-dideoxy-6oxo-griseorhodin $\mathrm{C}(4)$ (dissolved in $\mathrm{CH}_{3} \mathrm{CN}$, final conc. of $2.5 \%(v / v) \mathrm{CH}_{3} \mathrm{CN}$ in assay) and $1 \%(v / v)$ HPCD in aqueous solution at different $\mathrm{pH}$ values $(\mathrm{pH}=2$, $0.01 \mathrm{M} \mathrm{HCl}$ and $\mathrm{pH}=7.4$ ) was prepared. The mixtures were incubated at different temperatures $\left(4^{\circ} \mathrm{C}, 30^{\circ} \mathrm{C}, 50{ }^{\circ} \mathrm{C}\right)$ for $1 \mathrm{~h}(750 \mathrm{rpm})$. The reactions were quenched by addition of EtOAc/formic acid [9:1 $(v / v)]$ and extracted by vigorous shaking. The mixture was centrifuged for $30 \mathrm{~s}$ and the layers then separated. The solvents were removed under reduced pressure and the residues dissolved in $\mathrm{CH}_{3} \mathrm{CN}(40 \mu \mathrm{l})$. After centrifugation for $10 \mathrm{~min}$ at $18,000 \times \mathrm{g}$, samples were analyzed by HPLC.

Isolation of compound 12 and compound characterization. A. ianthinogenes spores $(60 \mu \mathrm{L})$ were inoculated into $60 \mathrm{~mL}$ GYM medium and grown at $30^{\circ} \mathrm{C}$ and $200 \mathrm{rpm}$ for $48 \mathrm{~h} .5 \mathrm{~mL}$ each of the preculture were then transferred into 10 flasks equipped with a stainless-steel spring containing $200 \mathrm{~mL}$ GYM medium and culture was continued at $30^{\circ} \mathrm{C}$ and $200 \mathrm{rpm}$ for $\sim 96 \mathrm{~h}$. The metabolite production was monitored by HPLC. If sufficient amounts of compound 12 were detected, the culture was harvested by centrifugation $\left(30 \mathrm{~min}, 4000 \times \mathrm{g}, 4^{\circ} \mathrm{C}\right)$. The separated supernatant was acidified with $\mathrm{HCl}(6 \mathrm{M}$ to $\mathrm{pH}=1)$ before dichloromethane $(700 \mathrm{~mL})$ was added. The mixture was stirred vigorously for $1 \mathrm{~h}$ followed by centrifugation $\left(10 \mathrm{~min}, 2000 \times g, 4^{\circ} \mathrm{C}\right)$. The solvent of the combined extracts was removed under reduced pressure and the residue dissolved in $\mathrm{CH}_{3} \mathrm{CN}$. After centrifugation for $10 \mathrm{~min}$ at $18,000 \times g$, samples were analyzed and compound $\mathbf{1 2}$ isolated by HPLC using a NUCLEODUR 100-5 C18ec column (varioprep, $250 \mathrm{~mm} \times 10 \mathrm{~mm} \mathrm{ID}$, $5 \mu \mathrm{M}$, Macherey-Nagel) coupled with a UNIVERSAL RP guard column $(4 \mathrm{~mm} \times$ $3 \mathrm{~mm}$ ID, Macherey-Nagel). The purification via semi-preparative HPLC yielded $31 \mathrm{mg}$ of dark purple solid. The product was analysed by ${ }^{1} \mathrm{H},{ }^{13} \mathrm{C}$ and $2 \mathrm{D} \mathrm{NMR}$, UV/Vis and ESI-HRMS. ${ }^{1} \mathrm{H}$ NMR $\left(600 \mathrm{MHz}\right.$, DMSO-d $\mathrm{d}_{6}, 1 \%$ TFA-d): $\delta 2.15$ (s, $3 \mathrm{H}), 2.34(\mathrm{~m}, 2 \mathrm{H}), 2.73-2.75(\mathrm{~m}, 2 \mathrm{H}), 3.91(\mathrm{~s}, 3 \mathrm{H}), 6.30$ (s, $1 \mathrm{H}), 6.62$ (brs, $1 \mathrm{H})$, $6.64(\mathrm{~s}, 1 \mathrm{H}), 9.30$ (brs, $1 \mathrm{H}), 10.75(\mathrm{~s}, 1 \mathrm{H}), 12.22(\mathrm{~s}, 1 \mathrm{H}) ;{ }^{13} \mathrm{C}$ NMR $(150 \mathrm{MHz}$, DMSO- $_{6}, 1 \%$ TFA-d): $\delta 18.6,24.4,34.1,56.9,103.9,104.1,109.8,116.2,128.2$, $137.4,141.7,147.3,151.0,158.2,166.2,194.2$; The signals of 16 carbon atoms are unambiguously assigned, also due to HSQC and HMBC signals. The remaining nine carbon atoms are not detectable possibly due to interaction with metals that is often observed for such compounds. However, IR spectroscopy and DFT calculations (Supplementary Fig. 48) as well as high-resolution MS/MS spectrometry and UV-Vis data (Supplementary Fig. 34: UV-Vis spectrum is indicative of intact western napthoquinone moiety of which some NMR signals are missing; the MS/ MS fragmentation pattern resembles compound 4) strongly support this structure UV/Vis $\left(\mathrm{CH}_{3} \mathrm{CN} / \mathrm{H}_{2} \mathrm{O}\right): \lambda 235,321,374,508 \mathrm{~nm} ; \mathrm{HRMS}(\mathrm{m} / \mathrm{z}):[\mathrm{M}+\mathrm{H}]^{+}$calcd. for $\mathrm{C}_{25} \mathrm{H}_{18} \mathrm{O}_{12}, 511.087$; found, 511.087 .

High Performance Liquid Chromatography. Compounds from enzymatic assays were analyzed or prepared by RP-HPLC on a 1100 series chromatographic system (Agilent Technologies) with a VP NUCLEODUR 100-5 C18ec column $(250 \times 10$ $\mathrm{mm}$ ID, $5 \mu \mathrm{M}$, Macherey-Nagel) and a UNIVERSAL RP guard column $(4 \times 3 \mathrm{~mm}$ ID, Macherey-Nagel). The mobile phases were water with $0.1 \%$ trifluoroacetic acid (TFA; solution A) and acetonitrile with $0.1 \%$ TFA (solution B). A gradient was run with $2 \%$ B from 0 to $1 \mathrm{~min}, 2-100 \%$ B from 1 to $15 \mathrm{~min}, 100-2 \%$ B from 20 to $21 \mathrm{~min}$ and $2 \%$ B from 21 to $24 \mathrm{~min}$. As second purification step for NMR samples, a Kinetex ${ }^{\circledast}$ Biphenyl $100 \AA$ column $(250 \times 10$ mm ID, $5 \mu \mathrm{M}$, Phenomenex $)$ was used with a UNIVERSAL RP guard column $(4 \times 3 \mathrm{~mm}$ ID, Macherey-Nagel). The 
mobile phases were water with $0.1 \%$ TFA or $0.1 \%$ formic acid (FA; solution A) and acetonitrile with $0.1 \%$ TFA or $0.1 \%$ FA (solution B). Isocratic methods were used for compound $6(90 \% \mathrm{~B})$ and compound $9(60 \% \mathrm{~B})$ at a flow rate of $3-5 \mathrm{~mL} / \mathrm{min}$ at $30{ }^{\circ} \mathrm{C}$ and absorbance was measured at $254 \mathrm{~nm}$ as well as $350 \mathrm{~nm}, 488 \mathrm{~nm}$, and $500 \mathrm{~nm}$. For analysis of the flavin cofactors, a NUCLEODUR Sphinx RP $(150 \times 3$ $\mathrm{mm}$ ID, $5 \mu \mathrm{M}$, Macherey-Nagel) with a UNIVERSAL RP guard column $(4 \times 3 \mathrm{~mm}$ ID, Macherey-Nagel) was used. The mobile phases were water with $0.1 \%$

TFA (solution A) and acetonitrile with $0.1 \%$ TFA (solution B). The following gradient was used: $2 \%$ B for $0-1 \mathrm{~min}, 2-100 \%$ B from 1 to $15 \mathrm{~min}, 100 \%$ B from 15 to $20 \mathrm{~min}$ and $2 \%$ B from 20 to $21 \mathrm{~min}$ with a flow rate of $1 \mathrm{~mL} / \mathrm{min}$ at $30^{\circ} \mathrm{C}$. Absorbance was measured at wavelengths of $210 \mathrm{~nm}, 254 \mathrm{~nm}, 260 \mathrm{~nm}$, and $280 \mathrm{~nm}$.

Chiral HPLC analysis. Dissolved and filtered samples of lenticulone (11) were analyzed by chiral HPLC on a 1100 series chromatographic system (Agilent Technologies) using a CHIRALPAK ${ }^{\oplus}$ AS-H $(250 \times 4.6 \mathrm{~mm}$ ID, $5 \mu \mathrm{M}$, Chiral Technologies Europe). The mobile phase was $100 \%$ ethanol. The flow rate was $0.25 \mathrm{~mL} / \mathrm{min}$ at $30^{\circ}$ $\mathrm{C}$ and absorbance was measured at $240 \mathrm{~nm}$ as well as $350 \mathrm{~nm}$, and $495 \mathrm{~nm}$. Additional tested columns: CHIRALPAK ${ }^{\oplus}$ AD-H $(250 \times 4.6 \mathrm{~mm}$ ID, $5 \mu \mathrm{M}$, Chiral Technologies Europe $)$, CHIRALCEL ${ }^{\circ} \mathrm{O}-\mathrm{H}(250 \times 4.6 \mathrm{~mm}$ ID, $5 \mu \mathrm{M}$, Chiral Technologies Europe $)$ and MultoHigh Chiral-AM-HR $(250 \times 4.6 \mathrm{~mm}$ ID, $5 \mu \mathrm{M}$, Isera $)$.

Chromatographic and mass spectral conditions. In total, $5 \mu \mathrm{L}$ of sample were injected and analyzed with an Agilent 6520 QTOF equipped with a dual ESI ion source. Chromatographic separation was performed with a flow rate of $0.75 \mathrm{~mL} / \mathrm{min}$, temperature controlled at $30^{\circ} \mathrm{C}$ in a column oven compartment with a NUCLEODUR Sphinx RP column $(150 \mathrm{~mm} \times 3 \mathrm{~mm}$ ID, $5 \mu \mathrm{M}$, Macherey-Nagel $)$ coupled with a UNIVERSAL RP guard column $(4 \mathrm{~mm} \times 3 \mathrm{~mm}$ ID, Macherey-Nagel). The gradient was as follows: $0-1.5 \mathrm{~min}, 10 \% \mathrm{~B} ; 1.5-22.5 \mathrm{~min}, 100 \% \mathrm{~B} ; 22.5-30 \mathrm{~min}, 100 \% \mathrm{~B}$; 30-30.1 min, $10 \% \mathrm{~B}$; and 30.1-37.5 min, 10\% B. Mobile phase A and mobile phase B consisted of water with $0.1 \%$ formic acid and acetonitrile with $0.1 \%$ formic acid, respectively. Reference mass correction was performed with constant infusion of purine and HP-0921 with $10 \mu \mathrm{L} /$ min through the secondary nebulizer needle. Mass spectral analysis was performed in full-scan mode and in $\mathrm{MS}^{2}$ mode. MS-Source parameters were as follows: Gas temperature, $250^{\circ} \mathrm{C}$; drying gas flow, $12 \mathrm{~L} / \mathrm{min}$; nebulizer pressure, $30 \mathrm{psi}$; capillary voltage, $3000 \mathrm{~V}$, fragmentor voltage, $150 \mathrm{~V}$; skimmer voltage, $65 \mathrm{~V}$; octopole voltage, $750 \mathrm{~V}$. Collision energy was set to $36 \mathrm{~V}$, yielding overall best fragmentation efficacy. Additional measurements of intermediates of enzyme assays were conducted with a Waters ACQUITY I-class UPLC in combination with a Waters HSS T3 (C18) column $(2.1 \mathrm{~mm} \times 100 \mathrm{~mm}, 1.8 \mu \mathrm{m}$ particle size $)$ coupled to a Waters Acquity photo diode array detector (Waters) and a Waters Synapt G2-Si HDMS electrospray ionization (ESI)/quadrupole time-of-flight (Q-TOF) system. The following software was used for MS and HPLC data analysis: Agilent MassHunter Workstation Acquisition B.04.00, Agilent OpenLAB ChemStation Edition Rev. C.01.07, Agilent MassHunter Workstation Qualitative Analysis B.08.01, Agilent OpenLAB ChemStation Edition Rev. C.01.07, and Waters MassLynx V4.1.

Photometric analysis. The spectra were recorded on UV-1800PC (inside the anaerobic chamber) and UV-1650PC spectrophotometers (Shimadzu Corp.) with a 10-mm QS quartz cuvette (Hellma Analytics).

Flash chromatography. Silica gel chromatography was performed using silica gel from Macherey-Nagel (60, particle size $0.040-0.063 \mathrm{~mm}$ ). The solvents for the mobile phase were chosen as described in the according sections.

Thin layer chromatography. TLC was performed using pre-coated TLC-sheets ALUGRAM $^{\circledR}$ Xtra SIL G/UV 254 (Macherey-Nagel). The compounds were detected with UV light ( $254 \mathrm{~nm}$ and $366 \mathrm{~nm})$.

Circular dichroism spectroscopy. CD spectroscopy of 7,8-dideoxy-6-oxo-griseorhodin C (4) and lenticulone (11) were recorded in a $0.2-\mathrm{mm}$ path length cuvette at $20^{\circ} \mathrm{C}$ with a Jasco J-810 spectropolarimeter (Jasco, Japan) equipped with a Peltier temperature controller PTC-423S (Jasco). The samples were dissolved in methanol, final concentrations: $0.6 \mathrm{mg} / \mathrm{mL}$ of compound 4 and $0.2 \mathrm{mg} / \mathrm{mL}$ of compound 11. Instrumental parameters: spectral range, $180-700 \mathrm{~nm}$, bandwidth, $1 \mathrm{~nm}$, scanning speed, $500 \mathrm{~nm} / \mathrm{min}$. The CD spectra shown in Supplementary Figs. 32 and 50 represent the average of five accumulations after solvent subtraction.

IR spectroscopy and density functional theory calculations. Solid state IR spectra of compounds $\mathbf{4}$ and $\mathbf{1 2}$ were recorded on a Tensor 27 FTIR spectrometer (Bruker) equipped with an attenuated total reflection (ATR) cell (Pike instruments) at a resolution of $4 \mathrm{~cm}^{-1}$. To facilitate the assignment of characteristic vibrational modes, 11 conformers of $\mathbf{4}$ and 27 conformers of $\mathbf{1 2}$ were modeled using the conformer search algorithm in SPARTAN (Wavefunction, Inc.). To identify the most abundant conformers for each compound, geometry optimization, energy calculation, and frequency calculation on all unique conformers were performed at the DFT level (B3LYP/6-31 G(d)) in Gaussian 16 Rev. C.01 (Gaussian, Inc.). A conformer was identified with $99 \%$ abundance for 4 and a conformer with $97 \%$ abundance for compound $\mathbf{1 2}$ (calculated with respect to $\Delta G$ ) that were used for comparison to the corresponding experimental spectra. IR bands were constructed with Lorentzian band shapes around each calculated intensity with a band width of $6 \mathrm{~cm}^{-1}$. Calculated frequencies were uniformly scaled by 0.97 . Characteristic bands were assigned through visualization of vibrational modes in GaussView 6 (Gaussian Inc.).

NMR spectroscopy. ${ }^{1} \mathrm{H}$ - and ${ }^{13} \mathrm{C}-\mathrm{NMR}$ spectra of compounds 9 and 11 were recorded with an Avance III HD 400 instrument (Bruker) $\left({ }^{1} \mathrm{H}: 400 \mathrm{MHz},{ }^{13} \mathrm{C}\right.$ : $100 \mathrm{MHz}$ ). All other ${ }^{1} \mathrm{H}$ - and ${ }^{13} \mathrm{C}$-NMR spectra were recorded with a FT-NMR DMX 600 instrument (Bruker) $\left({ }^{1} \mathrm{H}: 600 \mathrm{MHz},{ }^{13} \mathrm{C}: 150 \mathrm{MHz}\right)$. DMSO, $\mathrm{CDCl}_{3}$ and 1,4-dioxane- $\mathrm{d}_{8}$ were used as solvents. Chemical shifts refer to the $\delta$-scale and are reported in ppm with a solvent resonance as an internal standard $\left(\mathrm{CHCl}_{3}: \delta_{\mathrm{H}} 7.26\right.$ $\mathrm{CDCl}_{3}: \delta_{\mathrm{C}} 77.16$, DMSO: $\delta_{\mathrm{H}} 2.50, \delta_{\mathrm{C}} 39.51,1,4-$ dioxane-d $\left._{8}: \delta_{\mathrm{H}} 3.53\right)$. Data was analyzed and processed using the Bruker TopSpin 4.0.7 software.

Chemical structures and figures. Chemical structures for figures were drawn with PerkinElmer ChemDraw 19.0. UV and MS traces of enzymatic assays were plotted using GraphPaD Prism 8.3.0.

Reporting summary. Further information on research design is available in the Nature Research Reporting Summary linked to this article.

\section{Data availability}

The authors declare that the main data supporting the findings of this study are available within the article and its Supplementary Information files. Extra data are available from the corresponding author upon request.

Received: 28 October 2020; Accepted: 11 January 2021;

Published online: 04 March 2021

\section{References}

1. Hertweck, C., Luzhetskyy, A., Rebets, Y. \& Bechthold, A. Type II polyketide synthases: gaining a deeper insight into enzymatic teamwork. Nat. Prod. Rep. 24, 162-190 (2007)

2. Lackner, G. et al. Biosynthesis of pentangular polyphenols: deductions from the benastatin and griseorhodin pathways. J. Am. Chem. Soc. 129, 9306-9312 (2007).

3. Lin, Z. et al. Griseorhodins D-F, neuroactive intermediates and end products of post-PKS tailoring modification in Griseorhodin biosynthesis. J. Nat. Prod. 77, 1224-1230 (2014)

4. Kang, H.-S., Brady, S. F. \& Arixanthomycins, A.-C. Phylogeny-guided discovery of biologically active eDNA-derived pentangular polyphenols. ACS Chem. Biol. 9, 1267-1272 (2014).

5. Li, X., Wu, X., Zhu, J., Shen, Y. \& Amexanthomycins, A.-J. pentangular polyphenols produced by Amycolatopsis mediterranei S699 $\Delta$ rifA. Appl. Microbiol. Biotechnol. 102, 689-702 (2018).

6. Hofeditz, T. et al. Lysoquinone-TH1, a new polyphenolic tridecaketide produced by expressing the lysolipin minimal PKS II in streptomyces albus. Antibiotics 7, 53 (2018)

7. Wendt-Pienkowski, E. et al. Cloning, sequencing, analysis, and heterologous expression of the fredericamycin biosynthetic gene cluster from Streptomyces griseus. J. Am. Chem. Soc. 127, 16442-16452 (2005).

8. Ridley, C. P., Lee, H. Y. \& Khosla, C. Evolution of polyketide synthases in bacteria. Proc. Natl Acad. Sci. USA 105, 4595-4600 (2008).

9. Li, A. \& Piel, J. A gene cluster from a marine Streptomyces encoding the biosynthesis of the aromatic spiroketal polyketide griseorhodin A. Chem. Biol. 9, 1017-1026 (2002).

10. Yunt, Z. et al. Cleavage of four carbon-carbon bonds during biosynthesis of the griseorhodin a spiroketal pharmacophore. J. Am. Chem. Soc. 131, 2297-2305 (2009)

11. Brockmann, H. \& Renneberg, K.-H. Rubromycin, ein rotes Antibiotikum aus Actinomyceten. Naturwissenschaften 40, 59-60 (1953).

12. Atkinson, D. J. \& Brimble, M. A. Isolation, biological activity, biosynthesis and synthetic studies towards the rubromycin family of natural products. Nat. Prod. Rep. 32, 811-840 (2015).

13. Ueno, T. et al. Inhibition of human telomerase by rubromycins: implication of spiroketal system of the compounds as an active moiety. Biochemistry 39 , 5995-6002 (2000)

14. Siu, T., Qin, D. \& Danishefsky, S. J. The Total Synthesis of Heliquinomycinone. Angew. Chem. 40, 4713-4716 (2001).

15. Martin, R. et al. Collinone, a new recombinant angular polyketide antibiotic made by an engineered Streptomyces strain. J. Antibiot. 54, 239-249 (2001).

16. Walsh, C. T. \& Wencewicz, T. A. Flavoenzymes: versatile catalysts in biosynthetic pathways. Nat. Prod. Rep. 30, 175-200 (2013).

17. Matthews, A. et al. Aminoperoxide adducts expand the catalytic repertoire of flavin monooxygenases. Nat. Chem. Biol. 16, 556-563 (2020). 
18. Teufel, R. et al. Flavin-mediated dual oxidation controls an enzymatic Favorskii-type rearrangement. Nature 503, 552-556 (2013).

19. Teufel, R. Flavin-catalyzed redox tailoring reactions in natural product biosynthesis. Arch. Biochem. Biophys. 632, 20-27 (2017).

20. Fraaije, M. W. \& Mattevi, A. Flavoenzymes: diverse catalysts with recurrent features. Trends Biochem. Sci. 25, 126-132 (2000).

21. Huijbers, M. M. E., Montersino, S., Westphal, A. H., Tischler, D. \& van Berkel, W. J. H. Flavin dependent monooxygenases. Arch. Biochem. Biophys. 544, 2-17 (2014)

22. Toplak, M., Matthews, A. \& Teufel, R. The devil is in the details: The chemical basis and mechanistic versatility of flavoprotein monooxygenases. Arch. Biochem. Biophys. 698, 108732 (2021).

23. Palfey, B. A. \& McDonald, C. A. Control of catalysis in flavin-dependent monooxygenases. Arch. Biochem. Biophys. 493, 26-36 (2010).

24. Teufel, R. et al. Biochemical establishment and characterization of EncM's Flavin-N5-oxide cofactor. J. Am. Chem. Soc. 137, 8078-8085 (2015).

25. Ortega, H. E., Batista, J. M., Melo, W. G. P., Clardy, J. \& Pupo, M. T. Absolute configurations of griseorhodins A and C. Tetrahedron Lett. 58, 4721-4723 (2017).

26. Coronelli, C., Pagani, H., Bardone, M. R. \& Lancini, G. C. Purpuromycin, a new antibiotic isolated from Actinoplanes ianthinogenes N. sp. J. Antibiot. 27, 161-168 (1974).

27. Harunari, E. et al. Draft genome sequence of Streptomyces hyaluromycini MB-PO13T, a hyaluromycin producer. Stand. Genomic Sci. 13, 2 (2018).

28. Zhuang, X. et al. Characterization of Streptomyces piniterrae sp. nov. and identification of the putative gene cluster encoding the biosynthesis of heliquinomycins. Microorganisms 8, 495 (2020).

29. Medema, M. H., Takano, E. \& Breitling, R. Detecting sequence homology at the gene cluster level with multiGeneBlast. Mol. Biol. Evol. 30, 1218-1223 (2013).

30. Green, J. C., Burnett, G. L. \& Pettus, T. R. R. New strategies for natural products containing chroman spiroketals. Pure Appl. Chem. 84, 1621-1631 (2012).

31. Lindqvist, $Y$. et al. Structural basis for substrate recognition and specificity in aklavinone-11-hydroxylase from rhodomycin biosynthesis. J. Mol. Biol. 393, 966-977 (2009).

32. Kong, L. et al. A multifunctional monooxygenase $\mathrm{XanO} 4$ catalyzes xanthone formation in xantholipin biosynthesis via a cryptic demethoxylation. Cell Chem. Biol. 23, 508-516 (2016).

33. Wang, P., Bashiri, G., Gao, X., Sawaya, M. R. \& Tang, Y. Uncovering the enzymes that catalyze the final steps in oxytetracycline biosynthesis. J. Am. Chem. Soc. 135, 7138-7141 (2013).

34. Bosserman, M. A., Downey, T., Noinaj, N., Buchanan, S. K. \& Rohr, J. Molecular insight into substrate recognition and catalysis of Baeyer-Villiger monooxygenase MtmOIV, the key frame-modifying enzyme in the biosynthesis of anticancer agent mithramycin. ACS Chem. Biol. 8, 2466-2477 (2013).

35. Sollner, S., Deller, S., Macheroux, P. \& Palfey, B. A. Mechanism of flavin reduction and oxidation in the redox-sensing quinone reductase Lot6p from Saccharomyces cerevisiae. Biochemistry 48, 8636-8643 (2009).

36. Valton, J., Fontecave, M., Douki, T., Kendrew, S. G. \& Nivière, V. An aromatic hydroxylation reaction catalyzed by a two-component FMN-dependent Monooxygenase. The ActVA-ActVB system from Streptomyces coelicolor. J. Biol. Chem. 281, 27-35 (2006).

37. Ewing, T. A., Fraaije, M. W., Mattevi, A. \& van Berkel, W. J. H. The VAO/ PCMH flavoprotein family. Arch. Biochem. Biophys. 632, 104-117 (2017).

38. Conradt, D., Schätzle, M. A., Haas, J., Townsend, C. A. \& Müller, M. New insights into the conversion of versicolorin $\mathrm{A}$ in the biosynthesis of aflatoxin B1. J. Am. Chem. Soc. 137, 10867-10869 (2015).

39. Schätzle, M. A., Husain, S. M., Ferlaino, S. \& Müller, M. Tautomers of anthrahydroquinones: enzymatic reduction and implications for chrysophanol, monodictyphenone, and related xanthone biosyntheses. J. Am. Chem. Soc. 134, 14742-14745 (2012).

40. Husain, S. M., Schätzle, M. A., Lüdeke, S. \& Müller, M. Unprecedented role of hydronaphthoquinone tautomers in biosynthesis. Angew. Chem. 53, 9806-9811 (2014).

41. Sun, P. et al. Spiroketal formation and modification in avermectin biosynthesis involves a dual activity of AveC. J. Am. Chem. Soc. 135, 1540-1548 (2013).

42. Shichijo, Y. et al. Epoxide hydrolase Lsd19 for polyether formation in the biosynthesis of lasalocid A: direct experimental evidence on polyene-polyepoxide hypothesis in polyether biosynthesis. J. Am. Chem. Soc. 130, 12230-12231 (2008).

43. Grandner, J. M., Cacho, R. A., Tang, Y. \& Houk, K. N. Mechanism of the P450-catalyzed oxidative cyclization in the biosynthesis of griseofulvin. ACS Catal. 6, 4506-4511 (2016).

44. Xu, Z., Jakobi, K., Welzel, K. \& Hertweck, C. Biosynthesis of the antitumor agent chartreusin involves the oxidative rearrangement of an anthracyclic polyketide. Chem. Biol. 12, 579-588 (2005).

45. Tsypik, O. et al. Oxidative carbon backbone rearrangement in rishirilide biosynthesis. J. Am. Chem. Soc. 142, 5913-5917 (2020).

46. Piel, J. et al. Cloning, sequencing and analysis of the enterocin biosynthesis gene cluster from the marine isolate 'Streptomyces maritimus': evidence for the derailment of an aromatic polyketide synthase. Chem. Biol. 7, 943-955 (2000).
47. Xiang, L., Kalaitzis, J. A. \& Moore, B. S. EncM, a versatile enterocin biosynthetic enzyme involved in Favorskii oxidative rearrangement, aldol condensation, and heterocycle-forming reactions. Proc. Natl Acad. Sci. USA 101, 15609-15614 (2004).

48. Saleem-Batcha, R. et al. Enzymatic control of dioxygen binding and functionalization of the flavin cofactor. Proc. Natl Acad. Sci. USA 115 4909-4914 (2018).

49. Saleem-Batcha, R. \& Teufel, R. Insights into the enzymatic formation, chemical features, and biological role of the flavin-N5-oxide. Curr. Opin. Chem. Biol. 47, 47-53 (2018).

50. Cochrane, R. V. K. \& Vederas, J. C. Highly selective but multifunctional oxygenases in secondary metabolism. Acc. Chem. Res. 47, 3148-3161 (2014).

51. Jez, J. M., Ferrer, J. L., Bowman, M. E., Dixon, R. A. \& Noel, J. P. Dissection of malonyl-coenzyme A decarboxylation from polyketide formation in the reaction mechanism of a plant polyketide synthase. Biochemistry 39, 890-902 (2000).

52. Suetsuna, K. \& Osajima, Y. Isolation of structure of dideoxygriseorhodin C produced by a Streptomyces sp. Agric. Biol. Chem. 53, 241-242 (1989).

53. Panzone, G., Trani, A., Ferrari, P., Gastaldo, L. \& Colombo, L. Isolation and structure elucidation of 7,8-dideoxy-6-oxo-griseorhodin $\mathrm{C}$ produced by Actinoplanes ianthinogenes. J. Antibiot. 50, 665-670 (1997).

\section{Acknowledgements}

This work was supported by DFG grants awarded to R.T. (TE 931/2-1, TE 931/3-1, TE 931/4-1 and 235777276/GRK1976). We thank Christiane Müller, Irina Kempter (both TU Kaiserslautern) and Sascha Ferlaino (University of Freiburg) for NMR measurements and Matthias Boll (University of Freiburg) for technical support. The authors acknowledge support by the state of Baden-Württemberg through bwHPC and DFG through grant no INST 40/575-1 FUGG (JUSTUS 2 cluster).

\section{Author contributions}

B.F. conducted gene cloning, heterologous expression, protein purification, all mechanistic enzyme studies and their analysis, compound isolation, MS and NMR sample preparation and data evaluation, and wrote the SI. T.L. conducted chemical synthesis, compound isolation, and assisted in their structural elucidation by NMR. M.K. and B.K. conducted and analyzed MS measurements. Z.Y. and B.F. characterized secocollinone by NMR and MS. M.B. and S.L. conducted and analyzed CD and IR measurements. M.M. analyzed NMR data and assisted in planning of experiments. J.P. assisted in planning of experiments and data analysis. R.T. planned and analyzed the experiments and wrote the manuscript.

\section{Funding}

Open Access funding enabled and organized by Projekt DEAL.

\section{Competing interests}

The authors declare no competing interests.

\section{Additional information}

Supplementary information The online version contains supplementary material available at https://doi.org/10.1038/s41467-021-21432-9.

Correspondence and requests for materials should be addressed to R.T.

Peer review information Nature Communications thanks the anonymous reviewers for their contribution to the peer review of this work.

Reprints and permission information is available at http://www.nature.com/reprints

Publisher's note Springer Nature remains neutral with regard to jurisdictional claims in published maps and institutional affiliations.

Open Access This article is licensed under a Creative Commons Attribution 4.0 International License, which permits use, sharing, adaptation, distribution and reproduction in any medium or format, as long as you give appropriate credit to the original author(s) and the source, provide a link to the Creative Commons license, and indicate if changes were made. The images or other third party material in this article are included in the article's Creative Commons license, unless indicated otherwise in a credit line to the material. If material is not included in the article's Creative Commons license and your intended use is not permitted by statutory regulation or exceeds the permitted use, you will need to obtain permission directly from the copyright holder. To view a copy of this license, visit http://creativecommons.org/ licenses/by/4.0/

(c) The Author(s) 2021 